\title{
Patrones de asentamiento en la epoca agroalfarera de San Pedro de Atacama (norte de Chile) ${ }^{1}$
}

Agustín Llagostera M. ${ }^{2}$ y María Antonietta Costa J. ${ }^{2}$

\section{RESUMEN}

San Pedro de Atacama es una formación de oasis en el desierto de Atacama (norte de Chile) donde ocurrió una contínua e intensa ocupación humana desde tiempos prehispánicos -especialmente en la época agroalfarera- hasta la actualidad. Su potencial arqueológico motivó un notable trabajo en cementerios desde la década del cincuenta, pero muy poco relacionado con sitios habitacionales. Este es el primer intento de abordar la problemática de tales sitios en un marco de tipificación, secuencias, periodificación y patrones de asentamiento. Las prospecciones y el análisis ceramológico por distrito han permitido reconstruir la distribución sincrónica y las secuencias diacrónicas de los asentamientos, como un intento preliminar de conocer la ocupación y la dinámica del desarrollo sociocultural en esta localidad.

Las determinantes en las modalidades de los patrones de asentamiento durante la época agroalfarera en San Pedro de Atacama estuvieron relacionadas con el manejo del recurso hídrico y con la disponibilidad de espacios colonizables. Las evidencias iniciales de la ocupación humana se manifiestan preferentemente en la esquina Sur occidental de la formación de oasis (Tulor); las posteriores ocupaciones van cobrando fuerza en los distritos centrales (Quitor, Solcor, Larache y

1 Proyecto FONDECYT 90/0081

2 Instituto de Investigaciones Arqueológicas y Museo "R.P. Gustavo Le Paige S.J.", Universidad Católica del Norte, San Pedro de Atacama, museospa@entelchile.net
Séquitor), con una siguiente ocupación de los flancos occidental y oriental (Coyo y Solor), y algo en los distritos centro-meridionales (Tchaputchayna y Beter); en tanto, la tendencia tardía se extiende a los extremos norte y sur (Catarpe y Beter), a los flancos este y oeste (Solor y Yaye), así como también a Vilama.

\section{ABSTRACT}

San Pedro de Atacama is a cluster of oases in the Atacama Desert (north Chile) where there was a continuous and intense human occupation since prehispanic times, especially in the agropastoralist period, until the present day. It's archaeological potential motivated considerable work in cemeteries since the decade of the 50's, however very little research was conducted related to habitation sites. This is the first attempt to approach the problematic of these sites within a framework of typology, sequences, periodization, and settlement patterns. Prospecting and ceramic analysis by district have allowed the reconstruction of synchronic patterns of distribution and the diachronic sequence of settlements as a preliminary intent at understanding the occupation and dynamic of sociocultural development in this area.

The determining factors in the modalities of settlement pattern during the agropastoralist period in San Pedro de Atacama were related to the management of hydraulic resources and with the availability of space. The initial evidences of human occupation are preferentially manifested in the southwest corner of the cluster of oases (Tulor); later occupations gain prominence in the 
central districts (Quitor, Solcor, Larache and Séquitor), with a subsequent occupation of the eastern and western flanks (Coyo and Solor), and some in the southcentral districts (Tchaputchayna and Beter); the tendency in the later period is to expand to the extreme north and south (Catarpe and Beter), the eastern and western flanks (Solor and Yaye), as well as Vilama.

\section{Introducción}

San Pedro de Atacama es un establecimiento humano situado a $2400 \mathrm{~m} \mathrm{snm}$, en el extremo norte de la cuenca del Salar de Atacama, cuyo centro lo constituye el pueblo homónimo, a $22^{\circ} 55^{\prime}$ latitud $S$ y $68^{\circ} 12^{\prime}$ longitud $W$. Actualmente es el principal núcleo poblacional entre los varios pueblos que se ubican en la vertiente oriental del Salar de Atacama (Fig. 1). Su importancia deriva de una localización más favorable, con recursos de agua permanentes y con formación de suelos por la depositación del material de acarreo del río San Pedro y del río Vilama sobre los depósitos lacustres que han rellenado la cuenca (Aranda 1961-64). Tradicionalmente, la formación de oasis se la reconoce dividida en ayll $u^{3}$, los que, siguiendo su ubicación de norte a sur, reciben los siguientes nombres en idioma kunza: Catarpe, Quitor, Conde Duque, Solcor, Yaye, Larache, Tchecar, Sequitor, Vilama, Solor, Cucuter, Poconche, Beter, Coyo y Tulor.

Le Paige, hacia 1964, declara que, desde 1955 , había descubierto y excavado 47 cementerios indígenas en los ayllu de San Pedro de Atacama, obteniendo un total de 3.131 cuerpos (Le Paige 1964), con lo cual deja en evidencia la magnitud de la población que habitó los oasis de esta localidad durante el Período Agroalfarero. Sin embargo, Le Paige centró todo su interés exclusivamente en los cementerios y no se ocupó de los sitios habitacionales, dejando un vacío que tampoco fué llenado por otros arqueólogos.

Le Paige (1963) y Orellana (1963) propusieron las primeras secuencias para el Período

Se da el término de ayllu a los oasis que conforman la localidad de San Pedro de Atacama, involucrando cada uno una unidad física y social. Para nuestro objetivo, cada uno de ellos será un distrito arqueológico.
Agroalfarero de San Pedro de Atacama, basándose en los materiales funerarios excavados por el primero de los mencionados investigadores. Le Paige (1963:196-197) propuso una secuencia en siete fases que él llamo "niveles".

Posteriormente, Le Paige $(1964,1965)$ segrega una nueva fase a base de la cerámica que él llama "negra casi pulida" y que, de acuerdo a sus propios análisis, debería ubicarse entre el Nivel 4 y el Nivel 5. Por su parte, Orellana (1963) deslinda tres "facies" para el período en cuestión, siendo difícil correlacionar, en detalle, los contextos de su secuencia con los de la secuencia de Le Paige. Orellana tiene el mérito de intentar enmarcar la secuencia de San Pedro en un cuadro cronológico.

Hasta el momento, es Tarragó (1968) quien ha formulado la última secuencia para San Pedro de Atacama, considerando ocho "series" con algunos hitos cronológicos estimativos. A fin de poner a prueba la secuencia cultural de Tarragó, Berenguer y colaboradores (1986) analizaron por termoluminiscencia las cerámicas representativas de las ocho fases propuestas por ella, obteniendo una cronología respaldada por fechados absolutos y actualizando la secuencia original. Con posterioridad, Tarragó (1989), en su Tesis de Doctorado, incorporó ese marco cronológico a su esquema, sin variaciones sustanciales en relación a su propuesta del año 1968.

La primera publicación que, de alguna manera toca el tema de los sitios habitacionales, fué de Mostny, en "Ciudades Atacameñas", cuando describe y documenta, con fotos y planos, las construcciones de Catarpe, Quitor, Zapar y Peine, ubicándose sólo las dos primeras en San Pedro de Atacama. Determina, en general, que estos complejos arquitectónicos estaban ocupados todavía en la época incásica y, probablemente, también en la subsiguiente de la conquista española (Mostny 1949). Las anotaciones de esta arqueóloga se basaron en observaciones de superficie, puesto que no llevó a cabo excavaciones en ninguna de las ruinas mencionadas.

Las primeras publicaciones de una excavación en un sitio habitacional en San Pedro de Atacama, aunque a $30 \mathrm{~km}$ del poblado actual, correspondió a Serracino y colaboradores. En un primer artícu- 

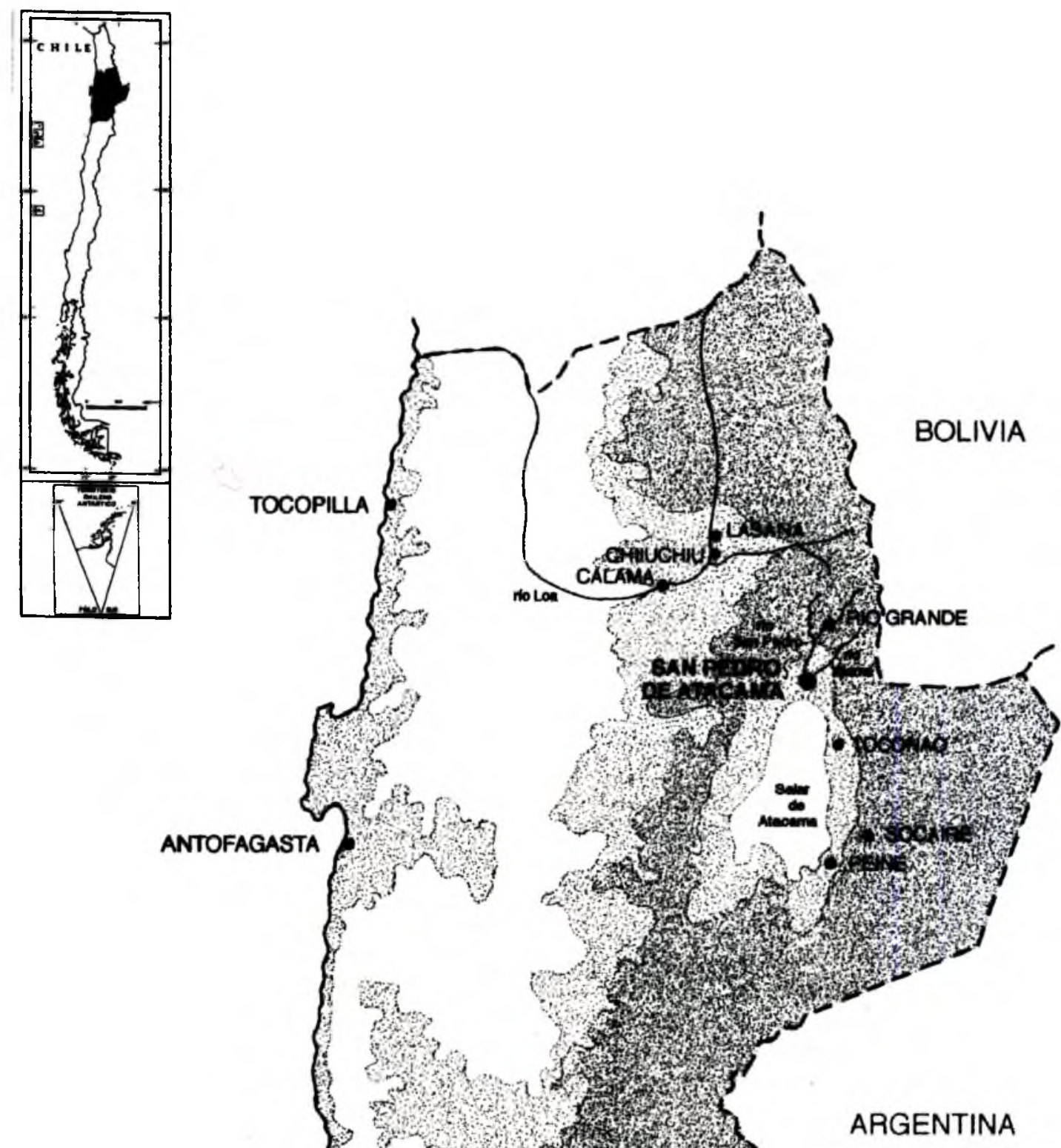

Figura 1

Ubicación de San Pedro de Atacama en la II región de Chile 
lo se presenta el Proyecto Guatín como informe de trabajo (Serracino et al. 1973), y en el segundo, "Investigaciones Arqueológicas en Guatín" (Serracino 1974), se entrega resultados y conclusiones. Los aportes más relevantes de este trabajo apuntan en tres direcciones. 1) Entregan mayores conocimientos para la cerámica del período tardío de San Pedro de Atacama, proponiendo dos sub-fases para la fase III de Orellana (1963) o IV de Le Paige (1965): una, preincaica y otra, anterior a ella, con cerámica negra engobada; 2) plantea que el origen de los pukara ${ }^{4}$ se debe buscar en los poblados rurales tipo Guatín, los que en la época tardía se convierten en zonas marginales con mínima conexión con los recintos fortificados; 3 ) detecta un notorio cambio de clima hacia un período de sequía o un régimen de lluvia semejante al actual, por el año $1000 \mathrm{DC}$, coincidente con la aparición de la cerámica negra engobada; 4) entrega un exhaustivo análisis del complejo estructural del sitio.

La próxima publicación sobre estratigrafía de un sitio habitacional corresponde a un yacimiento en San Pedro mismo y también es obra de Serracino: "Tulor-4: 4 pozos de sondeo" (Serracino 1976). Aquí, el arqueólogo dice que no encuentra los tipos de cerámica hasta entonces conocidos para las fases de San Pedro de Atacama; agrega que estos fragmentos se encuentran sobre un estrato precerámico y su forma es primitiva, por lo tanto, podrían ser tempranos y anteriores del rojo pulido. Da también otra alternativa: pudiera tratarse de cerámica doméstica y no funeraria, por lo cual no se le ha encontrado en las sepulturas.

Un segundo sitio en San Pedro de Atacama con excavación documentada fue Catarpe, sitio trabajado por Lynch e informado bajo el título de "Tambo incaico Catarpe-Este" (Lynch 1977). Lynch realizó un exhaustivo mapeo del lugar, distinguiendo una parte predominantemente local (oeste) y otra, de carácter público y de patrón incaico (este), con plazas, bodegas e instalaciones militares. En relación a la recolección de superficie y excavación, el investigador señala que la mayor parte de los fragmentos cerámicos se puede identificar con los tipos ya conocidos en el área de San Pedro (rojo violáceo, café pulido e inciso); las vasijas locales del período Inka están bien representadas, pero también se encuentran vasijas importadas, que podrían ser las propiamente incaicas; además hay vasijas del tipo Dupont y algunas que podrían ser postcolombinas.

La tercera y última publicación sobre excavaciones en un asentamiento agroalfarero de San Pedro de Atacama es la de "Investigaciones Arqueológicas en Tulor-1" (Llagostera et al. 1984). Los autores hacen un detallado análisis de la arquitectura, de la cerámica y de los restos orgánicos encontrados en las excavaciones estratigráficas de este sitio. Dan a conocer las primeras fechas radiocarbónicas para asentamientos agroalfareros de San Pedro de Atacama, ubicando la ocupación a comienzos de la era cristiana. Concluyen diciendo que, en una primera fase, pudo darse un sistema de asentamiento disperso, conformado por los diversos sitios que existen en el distrito de Tulor (v.gr.: Tulor 4), y que más tarde, uno de estos asentamientos (Tulor 1) logró la consolidación aldeana a través de un crecimiento más intenso que el resto. Esto habría estado incentivado por la necesidad de un núcleo centralizador que organizara las relaciones interregionales que se hacían cada vez más complejas.

Por lo expuesto, se puede apreciar que el trabajo en sitios habitacionales ha sido escaso y que todas las secuencias de desarrollo prehispánico para San Pedro de Atacama han sido hechas a base de contextos funerarios. En consecuencia, éste es el primer intento de abordar la problemática de sitios habitacionales en un marco de tipificación, secuencia, periodificación y patrones de asentamiento. Dada la envergadura y complejidad del problema, el presente trabajo debe ser considerado como un proyecto-base con miras a ser completado y perfeccionado.

\section{Tipologia de sitios en San Pedro de Atacama}

En San Pedro de Atacama es posible diferenciar dos grandes grupos de sitios: 1) sitios habitacionales y 2) sitios de enterramiento o cementerios. Arqueológicamente, los sitios habitacionales se caracterizan por un conjunto de restos que ponen en evidencia la realización de actividades domésticas en el lugar. Los subdividimos, a su vez, en 
sitios estructurados y no estructurados.

Los sitios habitacionales estructurados son todos aquellos que presentan vestigios de construcción (muros y/o recintos) para resguardo de sus habitantes y/o pertenencias. Por su parte, este tipo de sitios se puede subdividir en sitios defensivos y no defensivos. Los primeros están señalados por la ubicación en lugares de difícil acceso y por las evidencias de implementación para resguardo (muralla defensiva), denotando una clara intención estratégica de proteger y defender el sitio. Los segundos carecen de las características anteriores $y$, en consecuencia, se ubican en lugares fácilmente accesibles y expuestos.

Considerando las características constructivas de las estructuras, hemos definido como unidades simples aquellas constituídas por un solo recinto $y$, por unidades complejas, aquellas estructuras compuestas por varios recintos estrechamente yuxtapuestos.

La relación entre unidades será otro atributo a considerar en la categorización de sitios; es así como tenemos unidades aisladas y unidades asociadas. Las primeras se asientan como una sola unidad en un extenso paraje; en tanto las segundas, pueden asociarse formando conjuntos de unidades. Si estas unidades están muy próximas entre sí, hablaremos de conjunto aglutinado y si presentan espacios mayores entre ellas, de conjunto laxo. Una agrupación mayor compuesta por diversos tipos de conjuntos, la denominaremos complejo arquitectónico, definiéndolo de acuerdo a las categorías precedentes que lo componen.

Un último atributo a considerar en relación a los sitios habitacionales estructurados, es la forma de la planta de las estructuras; en el caso atacameño podemos distinguir recintos de planta rectangular, de planta circular, de planta mixta y de planta irregular.

Los sitios habitacionales no estructurados consisten en extensiones de superficie en las cuales se observan restos de actividad doméstica pero $\sin$ asociación evidente con vestigios de estructuras construidas. Puede ser que originalmente hayan existido cobijos o viviendas de material ligero o perecible, cuyas evidencias actualmente no son fáciles de detectar.

Los sitios de enterramiento o cementerios en San Pedro de Atacama son bastante homogéneos. No presentan ninguna evidencia superficial ni característica específica del lugar como para haber valorado su elección. El único rasgo que permite manejar una segregación clasificatoria pero que, al parecer, sólo es circunstancial, es el hecho de que algunos cementerios se ubican en terrenos planos y otros, en bordes o laderas de las terrazas fluviales.

\section{Clasificación y distribución de sitios por distri- tos}

De acuerdo al análisis de la información registrada en las fichas de catastro, se ha llevado a cabo la siguiente clasificación de los sitios, según los distritos prospectados ${ }^{5}$ :

\section{Distrito Beter (Fig. 2)}

A. Sitios habitacionales no estructurados: Sitios $2,4,5,6,7$ y 8 .

Se trata de amplias extensiones cubiertas con fragmentos de cerámica, material que ha quedado expuesto en los sectores despejados de arenales y dunas. Además, se encuentran restos líticos en moderada cantidad y muy escaso material perecible (óseos).

\section{B. Sitios habitacionales estructurados: Sitios 1 y} 3.

El Sitio 1 es un extenso complejo arquitectónico, compuesto por unidades simples y complejas, aisladas y asociadas, con habitaciones de plantas rectangulares, patios, callejones y tapiales. Se trata de un sitio construido bajo patrones hispánicos. Hay sectores donde la arquitectura se encuentra expuesta casi en su integridad y en buenas condi-

En esta publicación se ha considerado la primera etapa del proyecto sobre asentamientos -desarrollada a través del Proyecto Fondecyt 90/0081 - que involucra los distritos de Beter, Catarpe. Coyo, Quitor, Solor, Tchaputchayna, Tulor. Vilama y Yaye. Para la distribución de los sitios arqueológicos se utilizó, como base, el plano de regadío confeccionado por la Dirección de Riego (M.O.P), escala 1:20.000, s/f. 


\section{4}

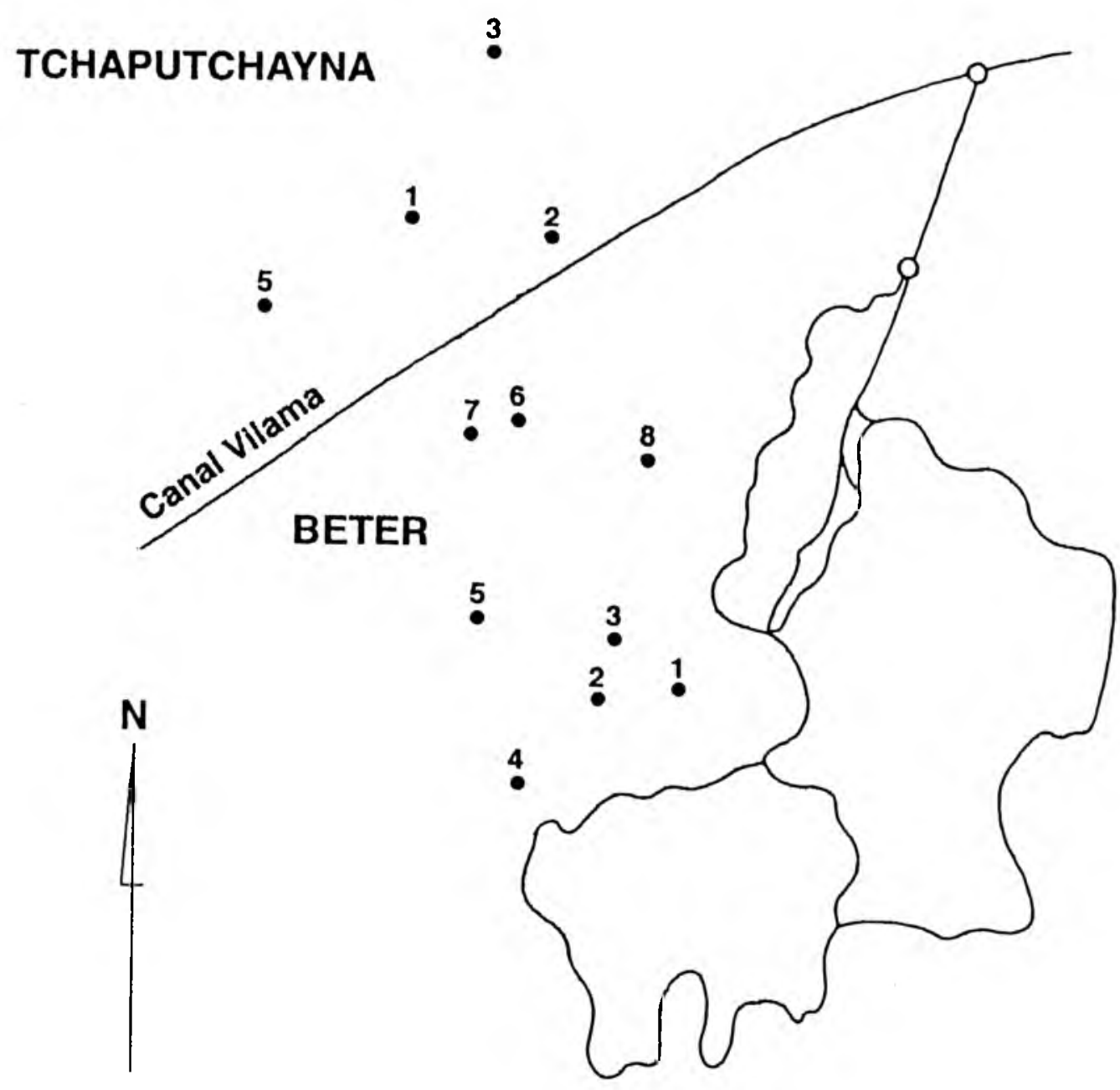

Figura 2

Distrito Tchaputchayna y Distrito Beter: distribución de sitios arqueológicos 
ciones; en cambio, en otros, el deterioro es evidente. En superficie: cerámica, líticos y óseos.

El Sitio 3 se encuentra totalmente cubierto por arena, quedando expuestos algunos cabezales de muros en ciertos sectores y, en otros, permanecen bajo dunas. Aparentemente se trata de una gran unidad compleja o de un conjunto aglutinado, con unidades de plantas rectangulares. En superficie: cerámica, líticos y óseos.

\section{Distrito Catarpe (Fig. 3)}

A. Sitios habitacionales estructurados: Sitios 1, 2, 3, 5, 9, 11 (Tambo Este) y 12 (Tambo Oeste).

Se trata de sitios con recintos de plantas rectangulares, con muros confeccionados de bloques de barro y argamasa. En estos recintos se observan fragmentos de cerámica, semillas de chañar, pequeñas mazorcas de maíz, concentraciones de fibra vegetal, fragmentos de instrumentos de molienda y posibles evidencias de fogones.

Destacan dentro de este grupo, por sus dimensiones y emplazamiento, los sitios 11 (Tambo Este) y 12 (Tambo Oeste) (Lynch 1977). Excepto por el hecho de estar ubicados en una meseta cortada abruptamente hacia el lado del río, el carácter defensivo de estos sitios no es evidente, ya que no tienen muros de protección y son plenamente accesibles por el flanco este. Tal vez, la utilización de esta meseta como lugar de asentamiento obedeció, más bien, a una alternativa más favorable que el lecho del mismo valle, para evitar el riesgo de las crecidas del río.

\section{B. Cementerios: Sitios $4,6,7$ y $10^{4}$.}

En general, estos sitios responden a las características de cementerios alterados y dentro de ellos podemos encontrar, al menos, cuatro tipos de enterratorios: tumbas en forma de pozos circulares (Sitio 6); tumbas y/o depresiones asociadas a recintos cuadrangulares (Sitio 4); tumbas en forma de depresiones circulares con pequeñas pircas delimitadoras (Sitio 7) y combinación de tumbas similares al patrón encontrado en los cementerios de Quitor y otras similares a las encontradas en Catarpe Tambo.

Le Paige (1964) señala que en Catarpe existen al menos cinco cementerios, de los cuales, por la información que nos entrega, se puede inferir que el sitio 4 corresponde al Cementerio 2 de Le Paige, el 6 corresponde al 5, el 7 al 1, el 10 al 4.

Sitio 4 (Catarpe 2, según Le Paige): No posee la cerámica roja típica de Catarpe 1; casi todas las tumbas contienen un plato de greda común y algunos vasitos muy rústicos. Sería más antigua que Catarpe 1 (Le Paige 1964:89)

Sitio 6 (Catarpe 5, según Le Paige): Le Paige sólo comenta que "es bastante distinto" (Le Paige 1964:89)

Sitio 7 (Catarpe 1, según Le Paige): Entregó cerámica roja, a veces adornada con líneas negras; vasos sencillos, de puro estilo incásico, con asas asímetricas y varios platos con pintura en el interior (Le Paige 1964:89)

Sitio 10 (Catarpe 4, según Le Paige): Su ajuar se asemeja más a Catarpe 2 (Le Paige 1964:89).

C) Campos de cultivo : Sitio 8 .

Este sitio presenta construcciones en forma de recintos y de pircas, asociados a probables campos de cultivos, también delimitados por muros.

\section{Distrito Coyo (Fig. 4)}

De acuerdo a la ubicación respecto al ayllu de Coyo, hemos distinguido Sector Norte, Sector Occidental y Sector Oriental.

Sector Norte

A. Sitios habitacionales no estructurados: Sitios $1,2,3,4,5$ y 6

Estos sitios se ubican en el margen noroeste de un antiguo cauce del río San Pedro. El sector se encuentra muy erosionado por escorrentías y rebalses del mismo río. Sus evidencias superficiales se limitan a abundantes fragmentos de cerámica.

Sector Occidental. ${ }^{7}$ ción de Le Paige. 


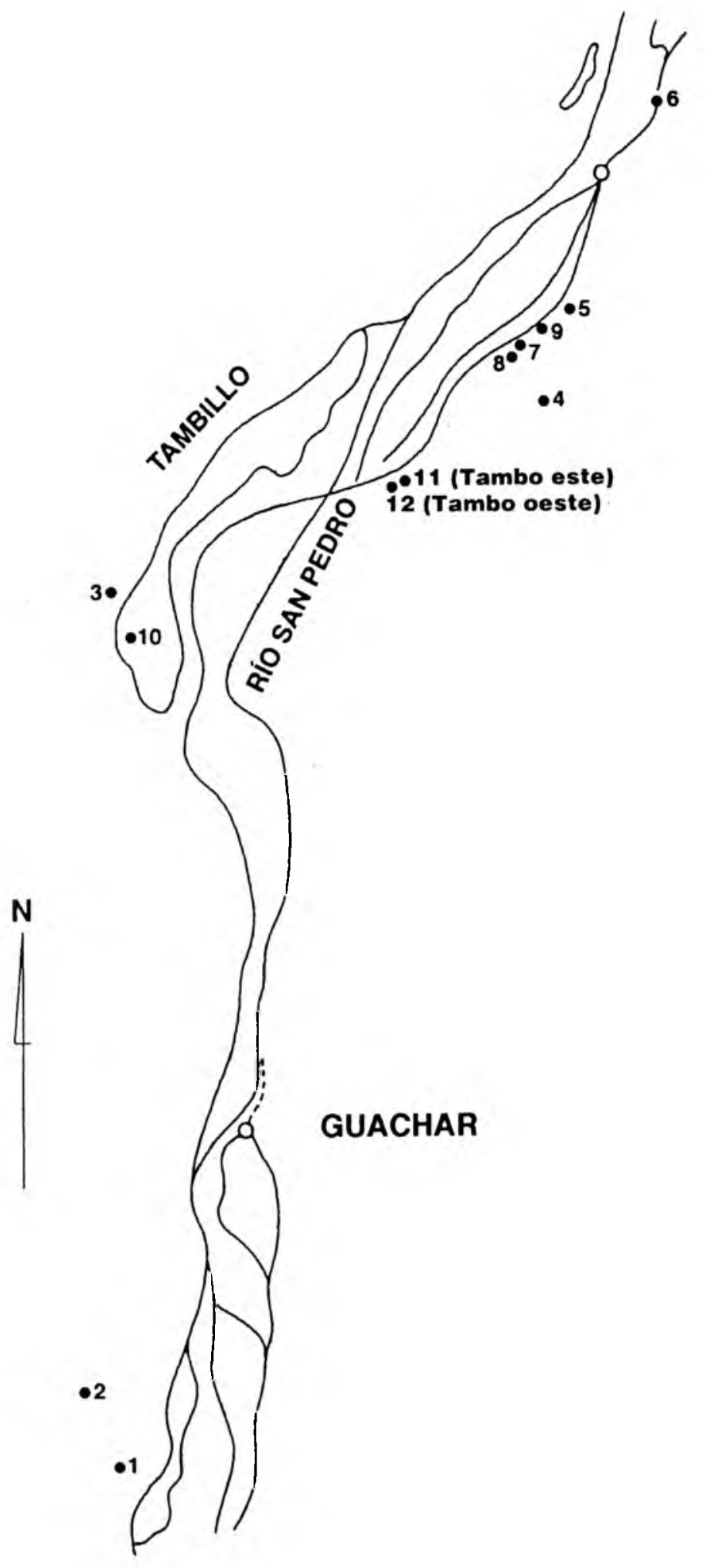

Figura 3

Distrito Catarpe: distribución de sitios arqueológicos 


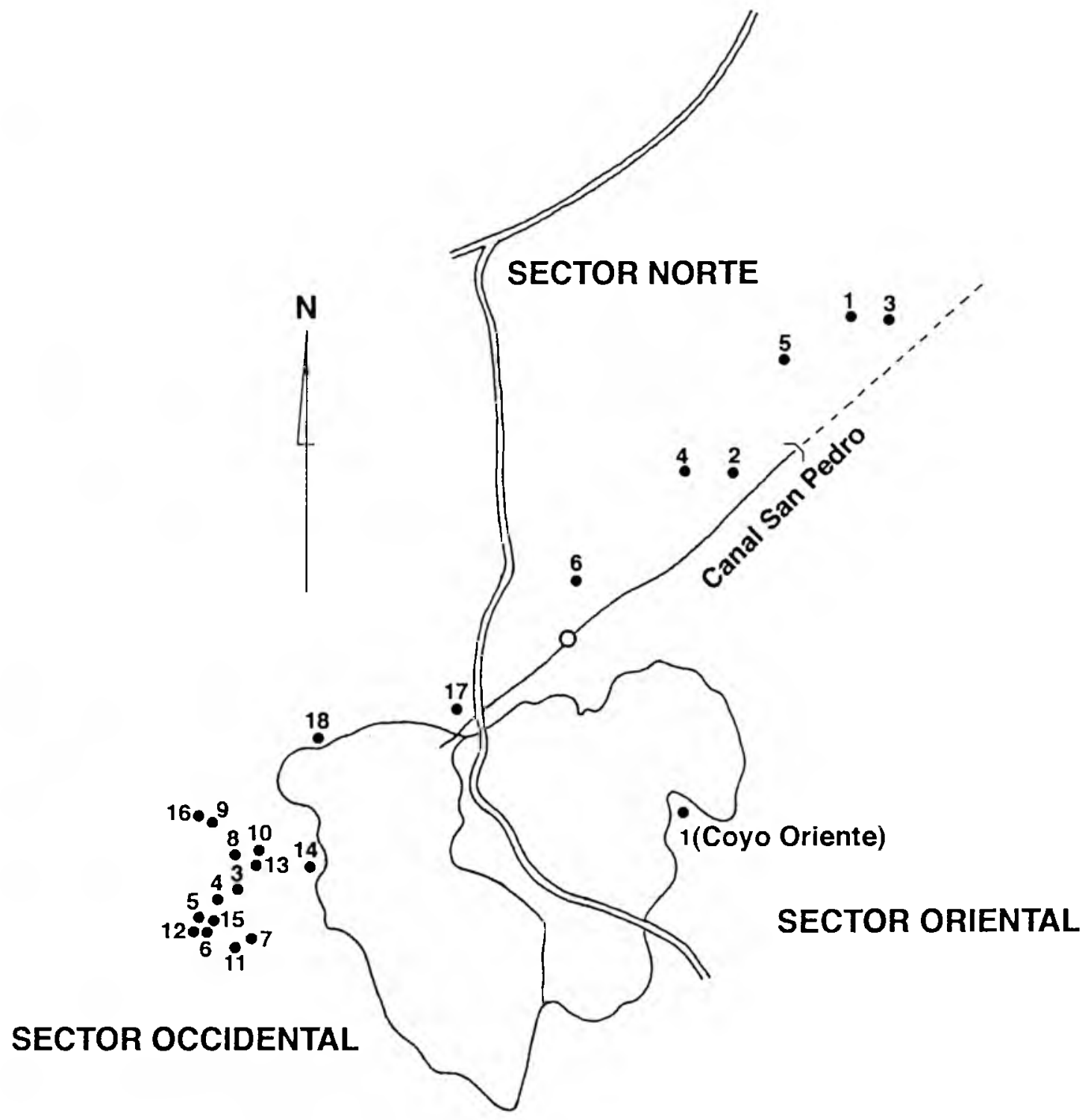

Figura 4

Distrito Coyo: distribución de sitios arqueológicos 
A. Sitios habitacionales no estructurados: Sitios $7,9,11,15,16$ y 18 .

Se trata de yacimientos con gran concentración de material arqueológico en superficie: fragmentos de cerámica, de líticos, de huesos, de madera y carbón de posibles fogones. Los sitios 9, 15, 16 y 18 presentan aspecto monticular. Cabe señalar que en el Sitio 15, además del material de superficie, existen evidencias de tumbas.

B. Sitios habitacionales estructurados: Sitios 4, $5,6,8,10,12,13,14$ y 17 .

En el Distrito Coyo hay sitios estructurados, con murallas de barro, que presentan recintos circulares (Sitios 4, 8, 12 y 13) como también rectangulares (Sitios 5, 6, 10, 14 y 17). Es posible observar gran cantidad de material cultural en superficie, como fragmentos cerámicos, manos de moler, fragmentos de morteros, lascas y fragmentos óseos. Los sitios 5, 13, 14 y 17 se encuentran bastante erosionados superficialmente.

\section{Cementerios: Sitios 3 y 15.}

El Sitio 3 es un cementerio del que se ha trabajado 50 tumbas las que, por su ergología y fechaciones, se ha definido como una ocupación correspondiente al final del Período Medio, y para el cual se dispone de tres fechas C14: $910 \pm 70 \mathrm{DC}$, $920 \pm 80$ DC y $960 \pm 50$ DC (Costa y Llagostera 1994: 75). El Sitio 15 se manifiesta como una formación monticular en la que se observan rasgos que hacen pensar que se trata de un cementerio ( $v$. gr.: palos enterrados que podrían estar indicando presencia de tumbas); junto con ésto, hay una gran concentración de material cultural en superficie, por lo que se trataría de un sitio mixto.

\section{Sector Oriental}

\section{A. Cementerio: Sitio 1.}

Corresponde al cementerio designado por Le Paige (1972-73) como Coyo Oriente, el que entregó 160 tumbas. El investigador señala que 58 de ellas se utilizados en la secuencia de sitios. pueden asignar a los períodos II y III y las demás, menos una, al período IV, con "concho de vino" o violáceo, pero con pocos ejemplares.

\section{Distrito Quitor (Fig. 5)}

\section{A. Sitios habitacionales estructurados : Sitio 10.}

Se trata de una estructura de planta probablemente circular, con muros construídos con técnica de pircado; a ella se asocian instrumentos de molienda, fragmentos cerámicos y óseos.

\section{B. Sitios habitacionales estructurados defensivos: Sitio 12 (Pukara).}

Este sitio ha sido descrito por Muñóz (1984). Se trata de un complejo arquitectónico, compuesto por 164 unidades de plantas mixtas, irregulares y algunas rectangulares. En superficie se observa fragmentos cerámicos, abundantes guijarros de río (proyectiles para honda) y escasos fragmentos líticos, representados por lascas fundamentalmente.

C. Cementerios: Sitios 1, 2, 3, 4, 5, 6, 7, 8, 9 y 11 .

Existen antecedentes de que estos sitios fueron cementerios (Le Paige 1964). Las características actuales son las siguientes: presencia de pozos circulares que corresponden a las tumbas excavadas; cantidad considerable de piedras de tamaño relativamente grande, las cuales no son comunes en el lugar. En la totalidad de los sitios se observan fragmentos de alfarería mayormente concentrados en las orillas de los pozos; los líticos están pobremente representados, distinguiéndose entre ellos, algunos instrumentos y adornos (cuentas de collar). Otros materiales asociados a estos sitios son: astillas óseas, fibras vegetales, fragmentos de textiles y palos. Todos estos sitios, excepto el Sitio 5 , se ubican en la planicie o en las laderas de la terraza oeste del río San Pedro. El Sitio 5 se sitúa en la terraza este. Todos estos cementerios fueron trabajados por Le Paige ${ }^{8}$.

Quitor 1: Le Paige no hace mayor referencia a la
En este caso hemos respetado la numeración de Le Paige. 


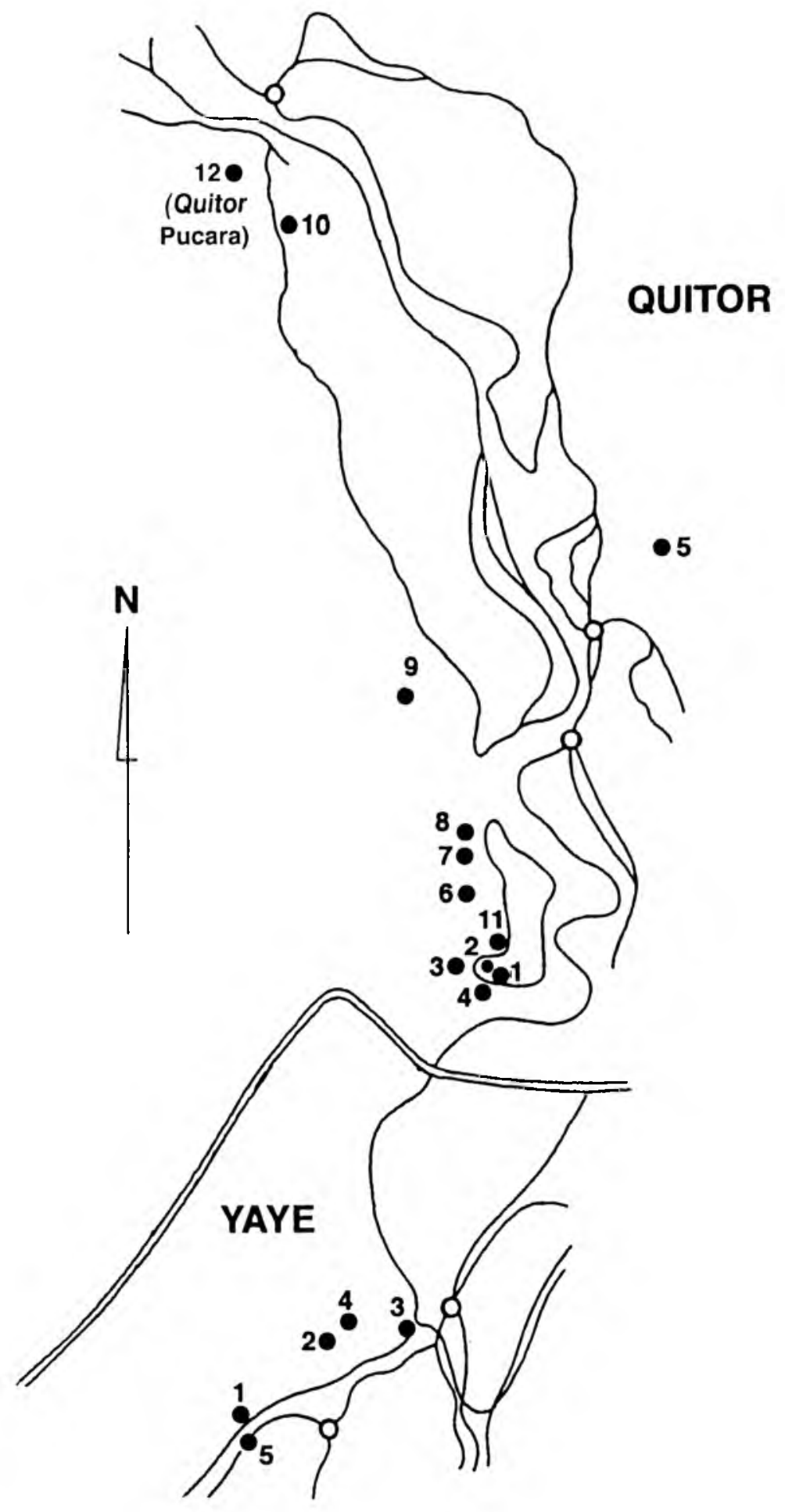

Figura 5

Distrito Quitor y Distrito Yaye: distribución de sitios arqueológicos 
cerámica de este cementerio; sólo señala que hay siete sepulturas que tenían "platos de greda comunes" (Le Paige 1964: 74-75).

Quitor 2: 235 tumbas que se distribuyen en: una zona con alfarería negra pulida, la más abundante; una zona con alfarería roja pulida y otra zona de transición (final de la fase II y antes de la III), con cerámica negra incisa (Le Paige 1964: 68-69; 1965: 19-21).

Quitor 3 y Quitor 4: ajuares muy pobres (Le Paige 1964: 75-76).

Quitor 5: 164 tumbas con 371 cuerpos. La parte oriental del cementerio presenta alfarería roja pulida; tanto en esta parte como en la parte central se encuentra alfarería negra pulida en conexión con la cultura Tiwanaku. En la parte Occidental aparece la misma alfarería negra bajo la forma de una taza gruesa con asa grande y núcleo rosado. Sería contemporáneo con Quitor 7 y Quitor 8. Se tiene una fecha C14 para este cementerio de $200 \pm 80$ DC (Núñez 1976) y cuatro fechas TL que van desde 440 a 720 DC (Berenguer 1986).

Quitor 6: fueron excavadas 566 tumbas y revelaría dos zonas: la meridional con alfarería negra pulida y ricos ajuares, y la septentrional, muy pobre, con alfarería negra "casi pulida" (Le Paige 1964: 66-68; 1965: 21-23). Se obtuvo una fecha C14 para este sitio de $250 \pm 150$ DC (Le Paige 1963) y una fecha TL de $580 \pm 140 \mathrm{DC}$ (Berenguer 1986). La prolongación norte de este sitio fue trabajada por Costa, resultando ser una fracción tardía del cementerio, compuesta de 42 tumbas, con tres fechas C14 que fluctúan entre 920 y 1240 DC

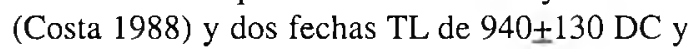
$1140 \pm 70$ DC (Berenguer 1986).

Quitor 7: aportó alfarería roja pulida y negra pulida, pero ningún ejemplar de negra "casi pulida" (Le Paige 1964: 63-64).

Quitor 8: presenta alfarería roja y negra pulida, pero la primera sólo se encuentra en la parte central y baja del cementerio, escasa en los bordes y en la parte ascendente, ausente en la parte alta. Varias tumbas de los bordes no tienen ajuar (Le Paige 1964: 64-65).
Quitor 9: se inhumaron 23 tumbas. "Mucho más reciente que Quitor 7 y 8: seguramente de la tercera fase del Agroalfarero atacameño: no presenta cerámica tipo San Pedro de At. negro pulido" (Le Paige 1964: 76-77). Este cementerio tiene una fecha radiocarbónica de 1050 $\$ 80$ DC (Núñez 1976).

Quitor 11: excavado por Le Paige (sin publicar).

\section{Distrito Solor (Fig. 6)}

Le Paige subdividió el Distrito de Solor en siete "campos", dentro de los cuales incluyó algunos de los sitios que él consideró más relevantes. Los sitios relevados por nosotros, adscribiéndolos a la sectorización de Le Paige, se distribuirían en la siguiente forma: campo 1: sitio 26; campo 2: sitio 25; campo 3: sitios 22, 23 y 24; campo 4: sitios $13,14,15,16,17 \mathrm{a}, 17 \mathrm{~b}, 18,19 \mathrm{a}, 19 \mathrm{~b}, 20$ y 21 ; campo 5: sitios $7,8,9,10,11$ y 12; campo 6: sitios $1,2,3,4,5$ y 6 .

\section{A. Sitios habitacionales no estructurados: Sitios $1,2,3,4,6,7,8,9,10,11,15,17 \mathrm{a}, 17 \mathrm{~b}, 19 \mathrm{a}, 19 \mathrm{~b}$ y 20 .}

Estos sitios presentan una concentración de material cultural en superficie (generalmente una gran concentración de fragmentos carámicos y una presencia menor de líticos). En forma más ocasional, también se puede apreciar la presencia de fragmentos y astillas óseas, fragmentos de madera y fibras vegetales, además de adornos (cuentas de collar).

\section{B. Sitios habitacionales estructurados: Sitios 13, 14, 16, y 18.}

Los cuatro sitios se caracterizan por presentar estructuras cuadrangulares construidas con paredes de barro. A esto se suma la presencia en superficie de fragmentos de cerámica, líticos y trozos de carbón.

El sitio 18 corresponde a lo que Le Paige denominó "ruinas del grupo 2" del Campo Solor 4 y, posiblemente, los sitios 14 y 13 , a las "ruinas del grupo 3" y "ruinas del grupo 4" del mismo campo. En estos sitios Le Paige encontró dos tipos de cementerios: "el primero muy hondo, más bajo que 


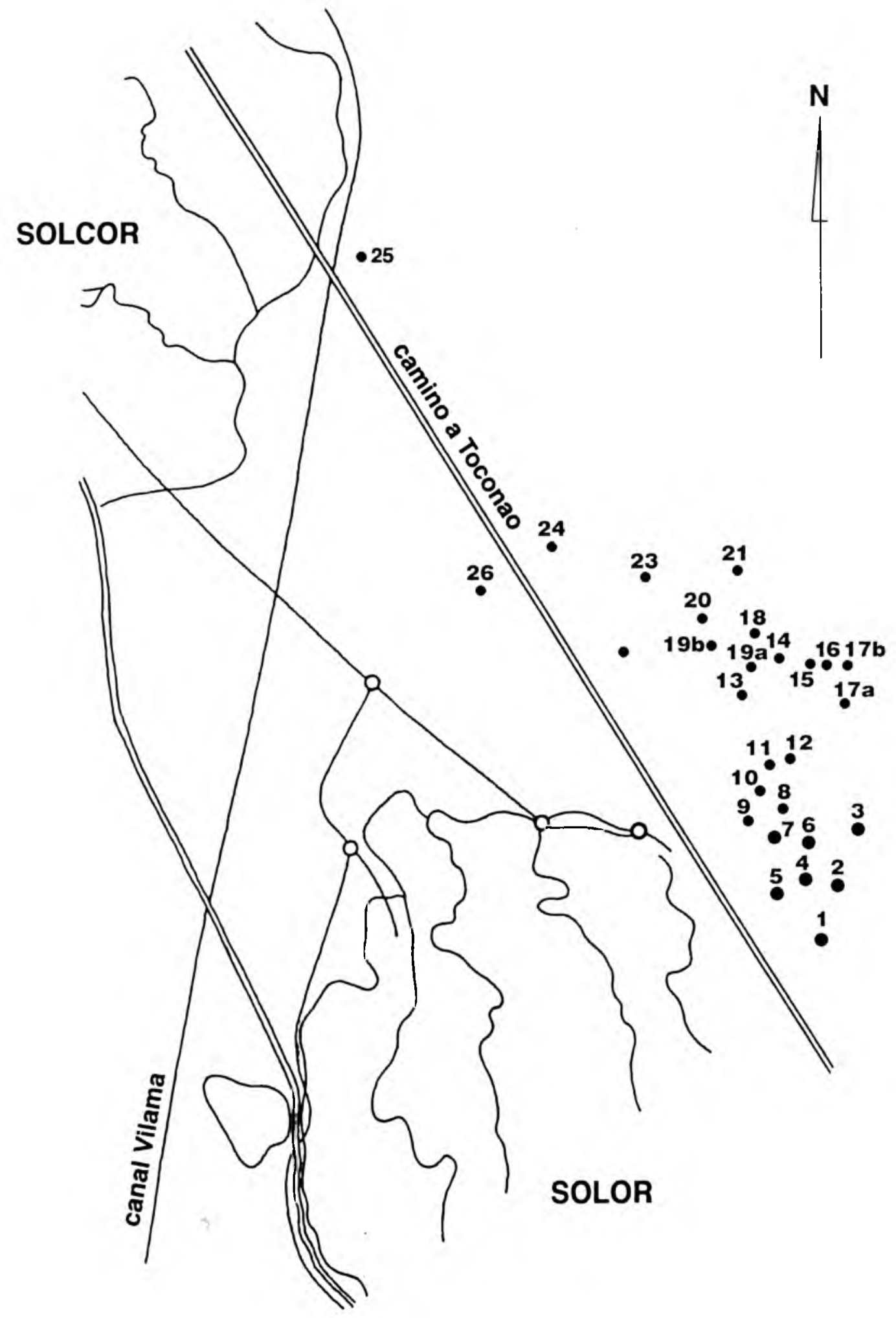

Figura 6

Distrito de Solor: distribución de sitios arqueológicos 
los cimientos, pero seguramente en relación con ellos...; el segundo es el entierro con urna" (Le Paige 1964: 81-84).

C. Cementerios: Sitios 5,12, 21, 22, 23, 24, 25 y 26.

Las características actuales de la superficie alterada delatan la función de estos sitios como lugares de enterratorios: presencia de cavidades de relativa profundidad, considerable cantidad de fragmentos óseos y huesos completos humanos, además de fragmentos cerámicos ${ }^{9}$.

Para algunos de ellos se encuentran referencias en Le Paige (1964).

El sitio 5 parecería corresponder a Solor 6 del mencionado investigador, quien obtuvo la fecha de $322 \pm 150$ DC y lo describe como un cementerio compuesto por dos pisos de entierros, señalando que llevan "el ajuar más pobre que hemos hallado: algunos platillos y vasitos comunes sencillos; algunas cuentas de liparita; un cincel de cobre; unos vestigios de tejidos en las tumbas superficiales" (Le Paige 1964: 74).

El sitio 12 correspondería a Solor 5 , el que se caracterizó por "entierros en grandes urnas $1,20 \mathrm{~m}$ de alto por $1 \mathrm{~m}$ de ancho en filas muy notorias" (Le Paige 1964: 84).

El sitio 21 podría corresponder al señalado como Solor 4 , con tumbas muy pobres acompañadas con "alfarería muy sencilla y común, especialmente con uso del engobe color concho de vino" (Le Paige 1964: 81-82). Existen dos fechas C14 para Solor 4 una, de $980 \pm 75$ DC y, otra, de $1180 \pm 65$ DC (Núñez 1976), a las que se suman cuatro fechas TL, que fluctúan entre 740 y 1220 DC (Berenguer et al. 1986).

Los sitios 22, 23 y 24 corresponderían respectivamente a los túmulos Sur, Centro y Norte del Campo Solor 3; según Le Paige, el Túmulo Sur presenta dos capas superpuestas de tumbas y el Túmulo Norte, tres. En el tercer piso (inferior) del Túmulo Norte y segundo piso (inferior) del Túmulo Sur, mucha alfarería negro pulida e incisa

9 No hemos mantenido la nomenclatura de Le Paige debido a que sus términos de "campo" y "grupo" ha hecho confusa su adscripción en terreno. con varios ceramios del tipo rojo pulido inciso. En el segundo piso (intermedio) del Túmulo Norte y en el primero (superior) del Túmulo Sur, alfarería negra pulida. En el primer piso (superior) del Túmulo Norte, ajuares muy pobres con alfarería común.

Al poniente del Túmulo Norte, Le Paige ubica un cementerio con más de 76 tumbas, caracterizado por la presencia de alfarería tipo San Pedro Rojo Pulido, junto con muchísima del tipo San Pedro Negro Pulido (Le Paige 1964: 56). Posiblemente, este sitio estuvo en el lugar por donde pasa la carretera a Toconao.

El sitio 25 sería Solor 2, sitio alterado antiguamente. "No quedó ningún entierro en el túmulo. El material recogido sobre el suelo es idéntico al de Solor 4: cerámica pintada concho de vino e incásica" (Le Paige 1964: 81).

El sitio 26 corresponde a Solor 1. Según Le Paige, este sitio es "idéntico y contemporáneo del grupo de Solor 4, con sus jarros, urnas y el material recogido sobre el suelo, especialmente pedazos de cerámica de Colla Pacajes" (Le Paige 1964: 81).

\section{Distrito Tchaputchayna (Fig. 2)}

\section{A. Sitios habitacionales no estructurados: Sitios $1,2,3$ y 4 .}

Se trata de grandes extensiones con fragmentación de cerámica expuesta; también se observan líticos e implementos de molienda. El Sitio 4 presenta formaciones monticulares.

\section{B. Cementerios : Sitio 5}

Sitio trabajado por Le Paige, quien diferencia dos tipos de tumbas en él: unas, más antiguas, con alfarerías negras pulidas y negras grabadas y otras, con entierros en urnas o con urnas al lado (Le Paige 1964:73).

\section{Distrito Tulor (Fig. 7)}

El Distrito Tulor fue descrito someramente por Le Paige (1974) como consistente en diez sitios distintos de murallas hechas con tapias y cinco sitios sin tapias, pero con fragmentos de cerámica, mor- 


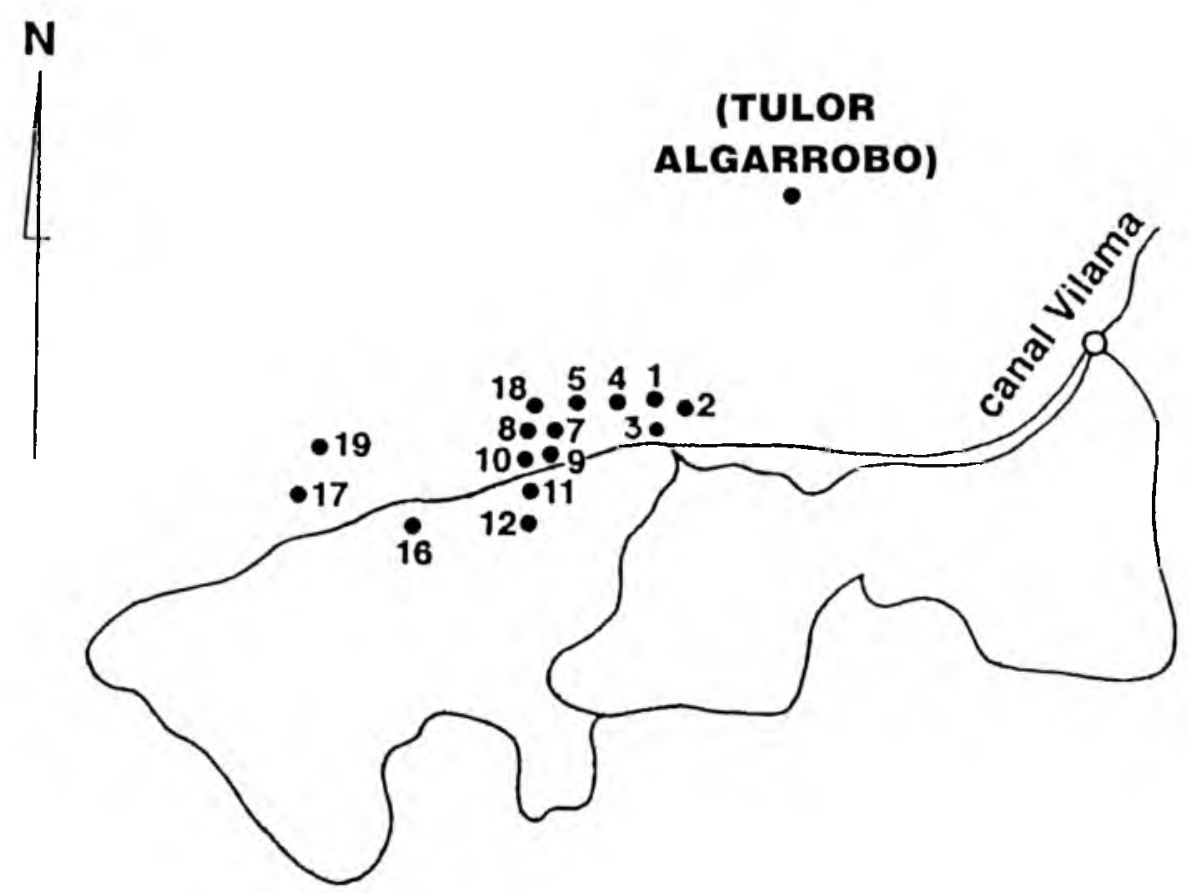

Figura 7

Distrito Tulor: distribución de sitios arqueológicos

teros y gran cantidad de partículas de huesos. La extensión de este yacimiento es de más de un kilómetro, y aquí la cerámica es muy abundante, especialmente la roja y la negra pulida; sin embargo, agrega, aparece también la cerámica "primitiva", en cantidad considerable. Junto con ésto, publica un plano con la ubicación relativa de 17 sitios.

A. Sitios habitacionales no estructurados: Sitios $6,13,14,15,16$ y 20 (Tulor Algarrobo).

Como en otros distritos, esta categoría se define por la depositación de material arqueológico en superficie y ningún otro tipo de formación asociada. Dentro del material expuesto se puede observar gran cantidad de fragmentos cerámicos, líticos y algunos trozos de madera.

B. Sitios habitacionales estructurados: Sitios 1 , $3,4,5,7,8,9,10,11,12,17,18$ y 19 .

En esta categoría del Distrito Tulor se incluyen recintos circulares, rectangulares y la combinación de ambas formas, que se agrupan en pequeños conjuntos o conjuntos aglutinados. Los recintos circulares, al igual que los rectangulares, están delimitados por paredes de barro. Además de las estructuras, también es posible observar en los sitios, acumulaciones superficiales de material arqueológico, fundamentalmente, fragmentos cerámicos, líticos, trozos de madera, de huesos y de carbón. El Sitio 1 es el mayor de los 12 sitios que componen el asentamiento y se trata de un conjunto habitacional estructurado, no defensivo, aglutinado, con 22 recintos de planta circular y otros irregulares (Llagostera et al. 1984) ${ }^{10}$. Se cuenta con dos fechas C14, una de 800 a $600 \mathrm{AC}$ y la otra de 200 a 245 DC (Llagostera et al. 1984); además, una fecha TL de $60 \pm 200$ DC (Berenguer et al. 1986).

Distrito Vilama (Fig. 8) 
A. Sitios habitacionales estructurados: Sitios 1, 4,5 (a, b, c, d, e) y 6 .

Todos estos sitios presentan recintos pircados, cuadrangulares. La densidad de fragmentación cerámica de superficie es relativamente menor que la que se observa en sitios de otros distritos.

\section{B. Sitios habitacionales estructurados defensivos:} Sitios 2 y 3.

Vilama 2 se ubica en la planicie de la terraza norte del río Vilama, aislado por el acantilado que cae al río y por quebradas secundarias. Ocupa una extensión aproximada de $7.200 \mathrm{~m} 2$ y está compuesto por 60 recintos agrupados en ocho conjuntos de unidades. La mayoría de los recintos es circular y los muros fueron construídos con piedras unidas con argamasa de barro y arena, mezclados con ceniza. El lado este, más accesible, está protegido por un muro de piedras que tiene 15 pequeñas troneras. Junto al muro se encuentran amontonamientos de piedras esféricas las que, sin duda, estaban destinadas a cumplir función de proyectiles. En superficie se encuentra abundante cerámica, líticos, algunos morteros y clastos; el material es más abundante al exterior de los recintos.

Vilama 3 se ubica hacia el sur de Vilama 2, en la misma formación de planicie, pero separado de aquél por una quebrada secundaria. Por el lado oeste está el acantilado y por el sur, la fuerte pendiente que se forma al producirse la expansión del valle. Los recintos, alrededor de 20 , se encuentran concentrados hacia el sector suroeste de la planicie. Un largo muro protege el borde sur y cierra el lado oeste; este último es el de más fácil acceso; queda, en consecuencia, un amplio espacio que ocupa los sectores oeste y norte. Los recintos son circulares y están construidos con el sistema de pircas. El material de superficie es escaso y se encuentra preferentemente en el interior de los recintos; llama la atención la ausencia de elementos de molienda, como morteros.

\section{Distrito Yaye (Fig. 5)}

A.Sitios habitacionales no estructurados: Sitio 5. Este sitio está definido por una alta concentración de material cultural. El material de superficie con- siste principalmente en fragmentos de carbón; fragmentos de cerámica (algunos de gran tamaño; gran concentración de fragmentos de huesos de animales (algunos quemados) y lascas.

\section{B. Cementerios: Sitios 1, 2, 3, y 4.}

Estos cementerios fueron excavados por Le Paige $(1964)^{11}$. La presencia de pozos circulares es la característica que delata a estos sitios como cementerios, correspondiendo a las tumbas excavadas. Se observan: fragmentos cerámicos, mayormente concentrados en las orillas de los pozos, astillas óseas, fragmentos de madera y de palos y grandes piedras que no presentan evidencias de haber sido instrumentos y que no son comunes en el entorno del sitio. La cantidad de pozos fluctúa entre 28 y 55 .

Yaye 1: "la ausencia absoluta de alfarería tipo San Pedro de At. negro pulido, e inciso, nos fuerza a pensar en la tercera fase del Agroalfarero atacameño" (Le Paige 1964: 78).

Yaye 2: 57 tumbas. "El ajuar es de los más pobres que hayamos encontrado... no podemos dudar se trate de la misma época de los otros tres cementerios de Yaye (tercera fase del Agroalfarero atacameño)" (Le Paige 1964: 78).

Yaye 3: "El ajuar es más rico que el del cementerio Yaye 2, pero inferior al de Yaye 1" (Le Paige 1964: 78-79).

Yaye 4: "El ajuar es idéntico al de Yaye 2" (Le Paige 1964: 79).

\section{Diagnóstico ceramológico por distrito}

Considerando que, en San Pedro de Atacama, el único elemento constante presente en todos los sitios es la cerámica y que, además, todas las secuencias arqueológicas de la localidad han sido construidas a base de la cerámica, hemos tomado este elemento como indicador de afiliación cronológico-cultural. Para tal efecto se llevó a cabo muestreos controlados de cerámica de superficie en todos los sitios y, además, pozos de sondeo en 


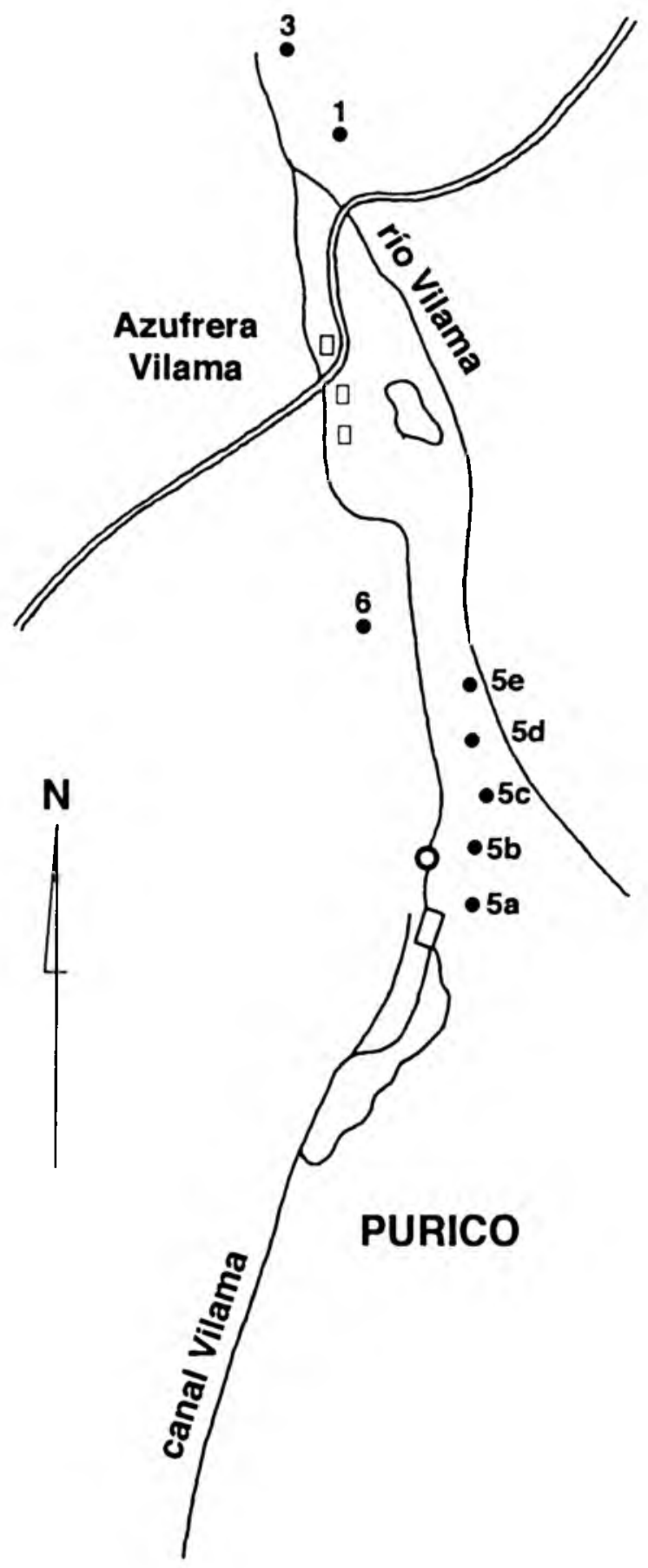

Figura 8

Distrito Vilama: distribución de sitios arqueológicos 
aquellos sitios promisorios de entregar un control de seriación vertical ${ }^{12}$.

La metodología utilizada para este análisis se basó en la ficha analítica propuesta inicialmente por Myriam Tarragó (Museo Etnográfico de Buenos Aires, Argentina) y modificada para el norte de Chile, por el equipo del Proyecto Turi (Museo Chileno de Arte Precolombino y Departamento de Antropología, Universidad de Chile). (cfr. Anexo 1).

El análisis tipológico y estadístico del material ceramológico obtenido de superficie nos permitió llegar a una primera caracterización de los sitios, al mismo tiempo que a un análisis comparativo entre ellos. En cada distrito los sitios se han ordenado en seriación cronológica relativa, desde el más temprano al más tardío ${ }^{13}$.

\section{Distrito Beter}

Beter 5: Alta frecuencia del tipo San Pedro Gris Pulido (28) y presencia de San Pedro Negro Pulido (27), además de los tipos San Pedro Café Pulido (29) y San Pedro Grueso Pulido (32). El tipo Rojo Alisado ambas caras (1) aparece en baja frecuencia.

Beter 2: Predominio de los tipos San Pedro Pulidos $(24,27,28,29$ y 31$)$, con presencia reducida del tipo Ayquina (3).

Beter 4: Bajan los porcentajes de los tipos San Pedro, $(24,27,28,29$ y 31$)$, aunque todavía son predominantes. Aumenta el porcentaje del tipo 3, junto con los tipos de Baños Rojos (10 y 11) y el tipo Dupont (8). También está presente el tipo 5.

Beter 6: Presencia más alta de los tipos del complejo Turi (3,4,5,7,8 y 9). Los tipos San Pedro están presentes pero en proporción mucho más baja. Se registra presencia de fragmentos foráneos (17) y del tipo 23.

Beter 8: El componente Turi se hace francamente predominante, mientras que el componente San

El resultado de las excavaciones será materia de otro artículo.

13 Los cementerios sin ocupación superficial han sido excluidos de esta análisis.
Pedro casi desaparece. Se registran fragmentos foráneos.

Beter 3: Predominio total del componente Turi, con primacía del Tipo $3 \mathrm{y}$, secundado por los tipos $2,4,5,8,10$ y 13. El componente San Pedro desaparece totalmente y tampoco hay foráneos.

Beter 1: Alto porcentaje del tipo 8, definido como cerámica colonial; también componentes del complejo Turi $(3,10$ y 11$)$.

La cerámica roja alisada (tipo 1) está en muy alta proporción en todos estos sitios.

\section{Distrito Catarpe}

Los sitios del conjunto Catarpe se caracterizan por un predominio del tipo Ayquina (3), seguido por los tipos de Baños Rojos ( 9 a 14). En Catarpe 10, Catarpe 3 y Catarpe Tambo Este (11) se concentra la mayor gama de estos últimos tipos. Los tipos foráneos están presentes en Catarpe 5, Catarpe 8 , Catarpe 10 y Catarpe Tambo Este (11). En Catarpe 5 y Catarpe 9 se hace presente el tipo 23. El componente San Pedro está ausente y la cerámica roja alisada (3) se mantiene en alta frecuencia.

\section{Distrito Coyo}

\section{Sector Norte}

Coyo Norte 6: Del Distrito Coyo Norte, este sitio es el que presenta la mayor frecuencia del componente San Pedro (24 y 33) y la menor proporción de componente Turi $(2$ y 3 ).

Coyo Norte 3: Aumenta el componente Turi (3 y 5) en relación al sitio 6 y baja notoriamente el componente San Pedro. Presencia de foráneos.

Coyo Norte 1 y 4: Alta frecuencia de componente Turi $(3,8,9,10$ y 13$)$ y muy baja del componente San Pedro.

Coyo Norte 2 y 5 : Aumenta aún más la presencia del componente Turi $(3,8,9$ y 10$)$; sin embargo, la frecuencia del componente San Pedro se mantiene similar a la de los sitios 1 y 4. En Coyo Norte 2, el porcentaje del tipo 8 es similar al del tipo 28 . En general se observa que cuando el tipo 28 
está ausente, o en proporción mínima, hay presencia del tipo 33 .

\section{Sector Occidental}

Se observa una alta frecuencia del componente San Pedro, especialmente en los sitios 4, 5, 6, 8, 9, 12, 15 y 16 . En los sitios 3, 4, 6 y 12 predominio absoluto del tipo 28 , seguido del 29 y, el Negro Pulido está en pequeña cantidad en los sitios 4,5 y 12. En los sitios 8, 9, 15 y 18 aparece en muy pequeña cantidad el tipo 3.

En $\operatorname{los}$ sitios 3, 7, 10 y 19 se aprecia un cierto equilibrio entre el componente San Pedro y el componente Turi.

En general, la frecuencia del componente San Pedro es levemente más baja en relación a los sitios anteriores

En los sitios 11 y 17 hay un predominio del tipo 3, aunque sin sobrepasar en exceso los tipos del componente San Pedro $(24,28,30$ y 32$)$.

\section{Distrito Quitor}

Quitor 12 (Pukara): Predominio del tipo Ayquina, seguido de Rojo Pintado, de foráneos y de Dupont. El tipo 1 es altamente predominante.

\section{Distrito Solor}

El sitio Solor 25 presenta el componente San Pedro $(24,28$ y 29$)$ y prácticamente nada del componente Turi. Escasa presencia foránea y alta, de cerámica alisada (1).

Los sitios $2,5,12,22$ y 23 muestran una alta presencia del componente San Pedro con el tipo 28 a la cabeza. Hay componente Turi en pequeña cantidad, aunque variado $(3,8,9,10,11,13$ y 14$)$. Presencia de tipos foráneos en Solor 22 y Solor 23 con proporción más alta que en los anteriores.

En los sitios 6, 9 y 21, el componente San Pedro disminuye, aunque mantiene una amplia gama (24, $27,28,30,31$ y 32). El componente Turi se incrementa a través de los tipos 3, 9 y de Baños Rojos. En Solor 6 se mantiene una presencia alta del componente San Pedro, con predominio del tipo 28. Hay presencia foránea en los tres sitios.

En los sitios 3, 8, 10, 18 y 20 hay predominancia del componente Turi, preferentemente representado por el tipo 3 y seguido por el tipo 8 y los de Baño Rojo. El componente San Pedro se encuentra sensiblemente disminuído. La cerámica foránea aparece en los cinco sitios, registrándose su mayor frecuencia en Solor 3 .

En los sitios 7, 11, 14, 15, 17, 19 y 26 el componente San Pedro tiende a desaparecer casi totalmente, mientras que el componente Turi predomina, con alto porcentaje del tipo 3 . En cinco de los sitios, el tipo 3 sobrepasa al tipo 1. Los tipos 8 y de Baños Rojos, especialmente el tipo 13, tienen un mayor porcentaje en este grupo de sitios que en otros. Los foráneos se hacen presentes en todos los sitios, excepto en Solor 17 y Solor 26 y, es notoria su presencia en Solor 19.

En los sitios 13, 16 y 24 hay total ausencia del componente San Pedro. El tipo 3 es el predominante entre el componente Turi. Aumenta el tipo 8, especialmente en Solor 24. En los tres sitios hay presencia de Baños Rojos y de foráneos.

Solor 1 presenta muy baja frecuencia tanto del componente San Pedro, como del componente Turi. Su mayor representatividad está dada por el tipo 1.

\section{Distrito Tchaputchayna}

En los sitios Tchaputchayna 3 y Tchaputchayna 4 predomina el componente San Pedro, destacándose los tipos 28 y 29 , además de la presencia del tipo 27. Ausencia total del componente Turi. En Tchaputchayna 4 se encontraron fragmentos de cerámica cuya pasta presenta mucha mica (23) y otros más, con pasta con inclusiones blancas (26). El tipo 1 se encuentra en bajo porcentaje.

Tchaputchayna 1 y Tchaputchayna 2 muestran una situación similar a los anteriores, pero con presencia del componente Turi. En el caso del sitio 1 este último componente está representado por los tipos de Baño Rojo (9 y 10) y en el sitio 2 por los tipos 2 y 3 . En el sitio 1 hay cerámica foránea. 


\section{Distrito Vilama}

Vilama $3,5 c$ y $5 e$ son sitios en los que está presente el componente de Baños Rojos, predominando, especialmente en los sitios 3 y 5 e, el tipo 3. En el sitio 5e hay, además, alta predominancia del tipo 20 , que reúne cerámicas de pasta de aspecto foráneo pero con inclusiones locales. También hay un porcentaje considerable del tipo 23, de pasta con mucha mica. Sólo dos fragmentos del tipo 28.

Los sitios 4, 5a y 5 b muestran ausencia del tipo 1 y del componente San Pedro. En Vilama 5b aparece representado el componente de Baños Rojos por el tipo 13. Lo que caracteriza a estos sitios es el predominio de cerámicas con pasta de aspecto foráneo, pero con inclusiones de aspecto local, predominando el tipo 20, acompañado de los tipos 18,19 y 21 . En Vilama 5a y Vilama 5 b hay presencia del tipo "vidriado" (22) y en los tres sitios se registra el tipo 23.

\section{Periodificación de los sitios}

De acuerdo a la composición ceramológica precedente y a la adscripción cronológica de los tipos predominantes, ha sido posible establecer una periodificación de los sitios, conformando los siguientes conjuntos.

Conjunto 1. Sitios con predominio de componentes del Período Temprano y del Período Medio: Beter 5, Coyo Occidental 4, Coyo Occidental 8, Coyo Occidental 12, Coyo Occidental 15, Solor 22 y Tchaputchayna 1.

Conjunto 2. Sitios con predominio de componentes del Período Medio: Beter 2, Coyo Occidental 5, Coyo Occidental 6, Coyo Occidental 16, Coyo Occidental 18, Solor 5 y Tchaputchayna 3.

Conjunto3. Sitios con predominio de componentes del Período Medio y del Período Intermedio: Beter 4, Coyo Norte 2, Coyo Norte 4, Coyo Occidental 14, Coyo Occidental 17, Solor 2, Solor 6, Solor 9, Solor 12, Solor 18, Solor 20, Solor 23, Solor 25 y Tchaputchayna 2.

Conjunto 4. Sitios con predominio de componentes del Período Intermedio (inicial): Coyo Norte 1 , Solor 7, Solor 10 , Solor 14 , Solor 15 , Solor 16 y Solor 17.
Conjunto 5. Sitios con predominio de componentes del Período Intermedio Tardío y del Período Tardio: Beter 3, Catarpe 3, Catarpe 12 (Tambo Oeste), Coyo Occidental 3, Coyo Occidental 10, Solor 11, Solor 19, Solor 24 y Vilama 5c.

Conjunto 6. Sitios con predominio de componentes del Período Tardío: Catarpe 5, Catarpe 8, Catarpe 9, Catarpe 11 (Tambo Este), Vilama 2 y Vilama 3.

Conjunto 7. Sitios con predominio de componentes del Período Tardío e Hispánico: Beter 1, Vilama 4 y Vilama 5 a.

\section{Discusión y conclusiones}

La secuencia postulada por Tarragó $(1968 ; 1989)$ sigue siendo la más prolija y vigente, por lo que la tomaremos como esquema base para el objetivo que nos hemos propuesto. La presencia de determinadas "clases de asociación" y la combinación de ellas, es lo que define las fases segregadas en la secuencia para San Pedro de Atacama. Tarragó (1989) distingue 14 clases de asociaciones que comprometen los diferentes tipos de alfarería (Anexo 2).

La Fase I ha sido definida hipotéticamente por la existencia de urnas de base cónica de Solor 6. Para la Fase II se señala que la cerámica está representada por "cántaros antropomorfos" negros o rojizos, los que se combinan con vasijas rojizas de las clases de asociación $\mathrm{N}^{\circ} 1,2$ y 3 . En la segunda mitad, se articula la clase 4. La Fase III es el período en que se va definiendo la tradición cerámica negra pulida propiamente dicha. Se hacen presentes las clases de asociación cerámicas $\mathrm{N}^{\circ} 4$ y 5 , predominando la última. En la Fase IV es característica la clase 6 del Negro Pulido clásico (Patrón A de Bravo y Llagostera 1986: 325), en todas sus variaciones. En un grado mucho menor, se combinan cuencos Negro y Rojo Grabado (clase 7 y 8). A nivel tecnológico, en la Fase $V$ se da el tránsito de la alfarería negra bruñida clásica a la gris plomiza de paredes más gruesas y de menor brillo (Patrón B de Bravo y Llagostera y "casi pulida" de Le Paige); la agrupación 11 de cerámica es característica en combinación con las clases 9 y 10 de los tazones grabados; también hay algunas tumbas sin cerámica. En la Fase VI, los reci- 
pientes cerámicos se limitan a escudillas grisáceas o son reemplazados por calabazas. En la Fase VII es probable que la combinación de platos con ollas y cántaros globulares de cerámica "rústica" represente el cambio de la fase anterior hacia las formas de combinación típica de cerámica Roja Violácea (clase 13) en sus varias combinaciones, y urnas Solor (tipo de asociación 26). En la Fase VIII se da la combinación de aribaloides y cántaros Inka Provincial, junto a Inka Paya y Concho de Vino.

La mayoría de los cementerios, al igual que los sitios habitacionales, son multicomponentes; es decir, se ha dado una ocupación contínua en ellos, de tal manera que han involucrado más de una fase.

Del análisis comparativo resulta que el grupo de cementerios más temprano está compuesto por Quitor 7 y Quitor 8, en los cuales aparecen las clases que definen a las fases II y III teniendo, por el contrario, muy baja representación las relacionadas con las Fases IV y V. Entre los sitios habitacionales, cabe señalar la escasísima presencia del tipo Rojo Pulido que sería el elemento más importante en la definición de las clases 1, 2, 3 y 4 .

Otro grupo de sitios de enterramiento ocupa una posición intermedia, ofreciendo la mejor representación de la Fase IV, una menor popularidad de la Fase III y una baja presencia de las clases de la Fase V. En ellos empieza a perfilarse, sin embargo, la clase 12. Este conjunto, bastante homogéneo, está integrado por Sequitor (parte oriental), Quitor 2 y Quitor 6. Tal como se señaló, la clase de asociación predominante en la Fase III, es la $\mathrm{N}^{\circ} 5$, en la cual aparece el tipo Negro Pulido como elemento exclusivo (Tarragó 1989). Este tipo (27 en nuestra tipología) se detecta en los sitios habitacionales Beter 2, 4, 5 y 8, Coyo Occidental 4, 5, $7,8,12,15,16,18$, Solor $2,5,6,9,11,16,18,19$, 21,22 y 23 , Tchaputchayna $1,2,3$ y 4 .

El cementerio de Quitor 5 resultaría ser el sitio con el mayor rango de variabilidad. Muy cerca de él y por su comportamiento también complejo, se ubica el área de Solor 3, con sus tres sectores, Túmulo Sur, Túmulo Norte y cementerio Occidental al Túmulo norte. En él, hay ausencia de la clase 1 y 2 , las siguientes 4 y 5 se dan en menor proporción que en Quitor 5, el máximo de popu- laridad está dado por las clases 6,7 y 8 (Fase IV) $\mathrm{y}$, en segundo término, las $\mathrm{N}^{\circ} 12,14$ y 15 correspondientes a la Fase VI.

Una de las características de la Fase IV, además de la presencia de alfarería Negra Pulida, es la presencia de alfarería grabada (24 en nuestra tipología), extendiéndose hasta la Fase V, en la clase de asociación $\mathrm{N}^{\circ}$ 9. Los sitios habitacionales que presentan este tipo de cerámica son: Beter 1, 2, 4, 6 y 8, Coyo Occidental 3, 4, 5, 6, 8, 9, 10, $11,12,15,16$ y 18 , Coyo Norte $1,2,5$ y 6 , Solor $2,3,5,8,9,10,12,16,20,21,22,23$ y 25 , Tchaputchayna 1 y 2 .

A continuación de Solor 3 sigue, entre los cementerios, el de Tchecar Túmulo Sur, que sirve de articulación entre sitios más tempranos y el conjunto de sitios tardíos que le suceden. Baja representación de las clases 6 y 11 y alta, de la clase 12 , asociadas a igualmente baja de 14 y 15 . Sin duda, aquí se expresa el tránsito de la Fase $\mathrm{V}$ hacia los comienzos del período tardío con Yaye. La Fase V está estructurada por las clases 9,10 y 11 , en las cuales las cerámicas grabadas se combinan con la cerámica Gris Pulido Grueso (Tarragó 1989). Nosotros hemos incorporado en esta fase, además del Gris Pulido Grueso (tipo 31), los tipos Negro Pulido Grueso (tipo 30) y Café Pulido Grueso (tipo 32); en consecuencia, como partícipes de la Fase $\mathrm{V}$, tenemos los siguientes sitios habitacionales: Beter 2, 4, 5 y 6, Coyo Occidental 3, 4, 5, 6, 7, 8, $9,10,11,12,15,16$ y 18 , Coyo Norte $2,3,4$ y 5 , Solor $2,5,6,8,9,12,15,20,21,23$ y 24 , Tchaputchayna 1 y 3 .

Finalmente, el otro conjunto importante y muy diagnóstico está integrado por los cementerios que sólo tienen representadas clases de asociación a partir de la clase 12, con total ausencia de todas las anteriores. Dentro del mismo se diferencian dos subconjuntos, uno constituido por los sitios de Quitor y Yaye, típicos representantes de la Fase VI y por otro, los sitios de Catarpe en los que disminuye la prominencia de la clase 12 , manifestándose mayormente las clases 13 y 26 de la Fase VII (Tarragó 1989).

La cerámica representativa de la clase 12 sería la que nosotros hemos definido como las variedades Ayquina (tipo 3) y Dupont (tipo 8) y, de la clase 
13, la Roja Violácea (tipos 9, 10, 11, 12, 13 y 14). En consecuencia, como sitios habitacionales con componente de la Fase VI (tipos 3 y 8), tenemos: Beter $1,2,3,4,6,7$ y 8 , Catarpe $1,3,5,8,9,10$, 11 y 12 , Coyo Occidental 3, 4, 7, 8, 9, 10, 11, 12, $14,15,16,17$ y 18 , Coyo Norte $1,2,3,4,5$ y 6 , Quitor 12, Solor 2, 3, 6, 7, 8, 9, 10, 11, 13, 14, 15, $16,17,18,19,20,21,22,23,24,25$ y 26 , Tchaputchayna 2 , Vilama $3,5 \mathrm{c}$ y $5 \mathrm{e}$.

Como sitios habitacionales con componente de la Fase VII (Tipos 9, 10, 11, 12, 13 y 14), se registran los siguientes: Beter 1, 3, 4, 6, 7 y 8, Catarpe $1,3,5,89,10,11$ y 12, Coyo Occidental 7, 14, 15, 16,17 y 19 , Coyo Norte 1,2 y 5 , Quitor 12 , Solor $1,2,3,5,6,7,8,9,10,11,12,13,14,15,16,17$, $18,19,20,21,22$ y 24 , Tchaputchayna 1 y 2 , Vilama $3,5 \mathrm{~b}, 5 \mathrm{c}$ y $5 \mathrm{e}$.

Las evidencias demuestran que antes de la Fase II, los asentamientos se ubican preferentemente en el borde de la puna y en las quebradas, con grupos propiamente pastores que encuentran en ese habitat, las condiciones adecuadas para desarrollarse. Hasta ahora sólo se conoce una fase que abarca desde los 1200 a los 500 AC y que está representada en la quebrada de Tulán y en Tilocalar, al sur de San Pedro de Atacama (Núñez 1992). En los oasis de San Pedro, hasta ahora, no se ha logrado evidencias que confirmen la Fase I postulada por Tarragó, por lo cual mantiene su carácter hipotético.

Próximo al término del milenio precristiano, se observa el desarrollo de una nueva modalidad que aparece muy relacionada con el ingreso del maíz. Los asentamientos resultantes han tenido que ubicarse al pie de la puna, buscando altitudes favorables a la fructificación de esta planta y próximos a la desembocadura de quebradas y ríos, con tierras húmedas para su cultivo. Los sitios de Tulor pueden ser considerados como el asentamiento más representativo de esta nueva formación socioeconómica de horticultores iniciales de pie de puna; también podría serlo Toconao Oriente ${ }^{14}$, sólo que, mientras en Tulor hemos encontrado los asentamientos y no los cementerios, en Toconao ha sucedido lo contrario. Estas nuevas manifestaciones son las que en San Pedro de Atacama han dado base para definir la Fase II o Fase Toconao (500 AC - $100 \mathrm{DC})$.
Los sitios de esta fase señalan que el patrón de asentamiento comprometía el borde suroeste de la formación de oasis de San Pedro de Atacama, específicamente el distrito de Tulor (Fig. 9). Ese paisaje, hoy cubierto por arenas y dunas, en aquel tiempo fue diferente: se trataba de la parte terminal del río San Pedro, lugar en el cual las aguas se infiltraban hacia el subsuelo conformando un área de terrenos anegados que favorecían la formación de vegas, lagunas y suelos húmedos, aptos para técnicas iniciales de horticultura. Alrededor de una veintena de sitios ha sido detectada allí, todos con las mismas características arquitectónicas definidas para Tulor 1 (Llagostera et al. 1984), excepto por sus menores tamaños, lo que plantea la hipótesis de que esta fase se habría iniciado con un sistema de asentamiento disperso, conformado por diversos sitios (v.gr.: Tulor 4), y que más tarde, uno de éstos (Tulor 1) logró la consolidación aldeana a través de un crecimiento más intenso que el resto; ello habría estado incentivado por la necesidad de un núcleo centralizador que organizara la complejidad agropecuaria y social que venía emergiendo.

Este habitat formativo fue drásticamente alterado por el avance del desierto en los dos primeros siglos del comienzo de la era cristiana; la incursión de los arenales en dirección noreste, comienza a cubrir las lagunas, vegas y tierras húmedas, obligando a las poblaciones a desplazarse hacia el norte, siguiendo el terminal activo del río el cual se iba replegando en esa dirección; es así que las ocupaciones posteriores se encuentran asentadas en Coyo y Beter. Es probable que este fenómeno estuvo asociado a un momento de clima más seco, causante de la disminución del cauce de los ríos.

En los tiempos inmediatamente posteriores a la Fase Toconao comienza a definirse un patrón ceramístico propiamente atacameño, a través de las clásicas vasijas negras pulidas, siendo esta característica la que señalaría los sitios que pertenecen a la Fase III (100 DC - 400 DC). Por su parte, la Fase IV (400 DC - 700 DC) se define como un

Toconao Oriente es un sitio arqueológico que se ubica en el poblado de Toconao (La Paige 1972-73), a $38 \mathrm{~km}$ de San Pedro de Atacama, con un rango de fechas TL de $350 \mathrm{AC}$ a $690 \mathrm{DC}$ (Berenguer et al. 1986). 


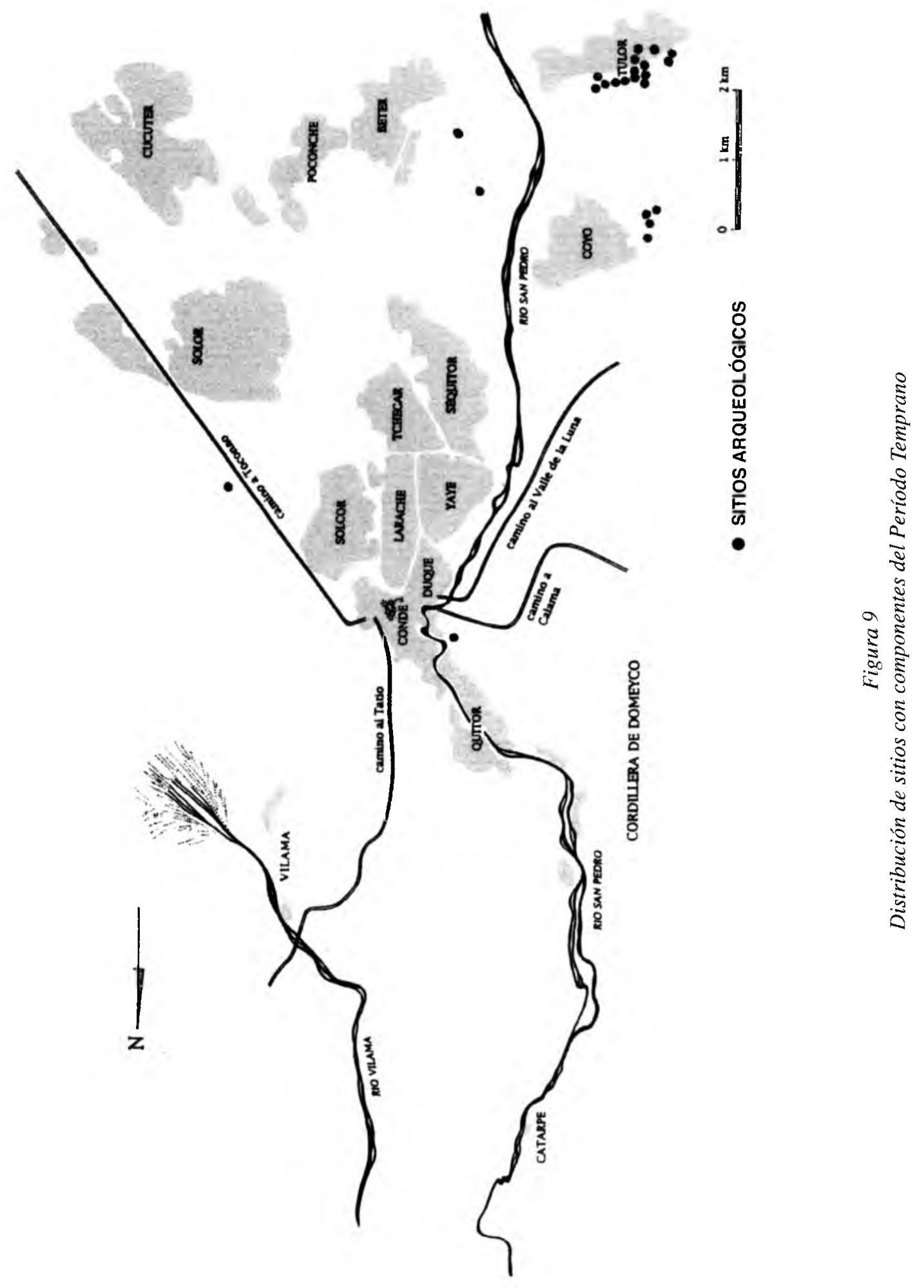


período de fuerte inflexión en las tradiciones tecnológicas, en las costumbres y en las creencias. (Tarragó 1989). A través de los ajuares funerarios se observa una mayor complejidad cultural, así como evidencias de una organización sociopolítica en torno a jefes-shamanes.

El patrón de asentamiento de esta fase está incorporando, a través de cementerios y sitios habitacionales, los distritos de Beter (con cinco sitios), Coyo (con 9 sitios en el sector Occidental), Cúcuter (con un sitio), Larache (con un sitio), Poconche (con un sitio) (cfr. Le Paige), Quitor (con cinco sitios), Séquitor (con dos sitios), Solcor (con un sitio) (Bravo y Llagostera 1986), Solor (con doce sitios) y Tchaputchayna (con cuatro sitios). En la Fase Quitor se produjo la ocupación de prácticamente todos los distritos de San Pedro de Atacama, con una mayor preferencia por los distritos centrales. Esta tendencia se observa hasta hoy, y que ha sido la causal de la destrucción de las evidencias arqueológicas en dichos sectores. Por la dispersión de los sitios arqueológicos, se puede asegurar que la gente estaba aprovechando el gran delta conformado por las ramificaciones terminales en espacio abierto de los ríos Vilama y San Pedro. Se puede pensar que, de alguna manera, ya se estaba ejerciendo un control más activo del agua, probablemente, a través de canales.

Fase V o Fase Coyo, ha sido ubicada cronológicamente entre 700 y $950 \mathrm{DC}$, pero, basándonos en nuevas dataciones radiocarbónicas, vemos que se hace necesario reajustar esta fase. Para esta fase, en Solcor 3 (Llagostera et al. 1988), tenemos fechas que van de 480 a $920 \mathrm{DC}$ y, para el sitio 1 de Coyo Oriente, fechas de 639 a 910 DC (Oakland 1992), con lo que rebajaríamos el inicio de ella a 500 DC, ocupando la totalidad del Período Medio. Esta Fase Coyo está señalada principalmente por las influencias de Tiwanaku; es así que, a partir de $500 \mathrm{DC}$, se produjo un cambio notorio en San Pedro de Atacama que coincidió con el ingreso de objetos tiwanakotas. Este cambio afectó a todo el bagaje artefactual, pero quedó sensiblemente registrado en la modificación total de la técnica y del estilo de la alfarería (Gris Pulida Gruesa de Tarragó o negra "casi pulida" de Le Paige), la que, sin embargo, se reformuló dentro de patrones propios, no reflejando ninguna influencia de Tiwanaku.
El patrón de asentamiento, de alguna manera, mantiene las características del patrón anterior, y en gran parte se ha estructurado a base de la continuidad ocupacional de las mismas áreas que señalamos anteriormente (Fig. 10); es así que la totalidad de los cementerios de la Fase Quitor muestra continuidad hacia la Fase Coyo. Sin embargo, varios de los sitios habitacionales son establecimientos nuevos dentro de los sectores ya conocidos. Los distritos que presentan componentes de la Fase Coyo son: Beter (con seis sitios), Coyo (con doce sitios en el sector Occidental y, cuatro en el sector norte), Solor (con 14 sitios) y Tchaputchayna (con dos sitios). Algunos de estos sitios se manifiestan como sitios habitacionales estructurados de cierta complejidad, con recintos de plantas circulares, en ciertos casos, y combinados con plantas rectangulares, en otros. La más amplia distribución de la ocupación humana en esta fase aumenta las probabilidades del uso de canales.

Entre los sitios que no presentan continuidad en su ocupación, con la fase anterior, destaca el cementerio de Coyo Oriente 1. Este aparece como una expansión de la gente de la Fase Coyo hacia un lugar que no tenía antecedentes previos de ocupación; la alta frecuencia de martilllos encontrados en las tumbas hace pensar que esta situación responde a una derivación de un grupo con fines específicos de especialización en labores de cantería y minería.

La Fase Yaye (950 DC - 1.200 DC) corresponde a una época en que han finalizado las situaciones de interacción con Tiwanaku. La cantidad y la calidad de los ajuares fúnebres muestran una perceptible disminución. Los recipientes cerámicos se limitan a escudillas grisáceas o son reemplazados por calabazas. El conjunto de la fase sugiere que las tradiciones socio-culturales se han encauzado por un rumbo muy distinto al de las épocas previas (Tarragó 1989). El patrón de asentamiento aparece bastante reducido en relación a la amplitud manifestada anteriormente. Se ocupan nuevos lugares de enterramiento, como es el propio ayllu de Yaye pero, por otro lado, se observa una notable reducción de evidencias de esta fase en las otras áreas. Sólo se registra un sitio en Coyo (Coyo Norte 1) y la población aparece concentrada en seis sitios de Solor. 


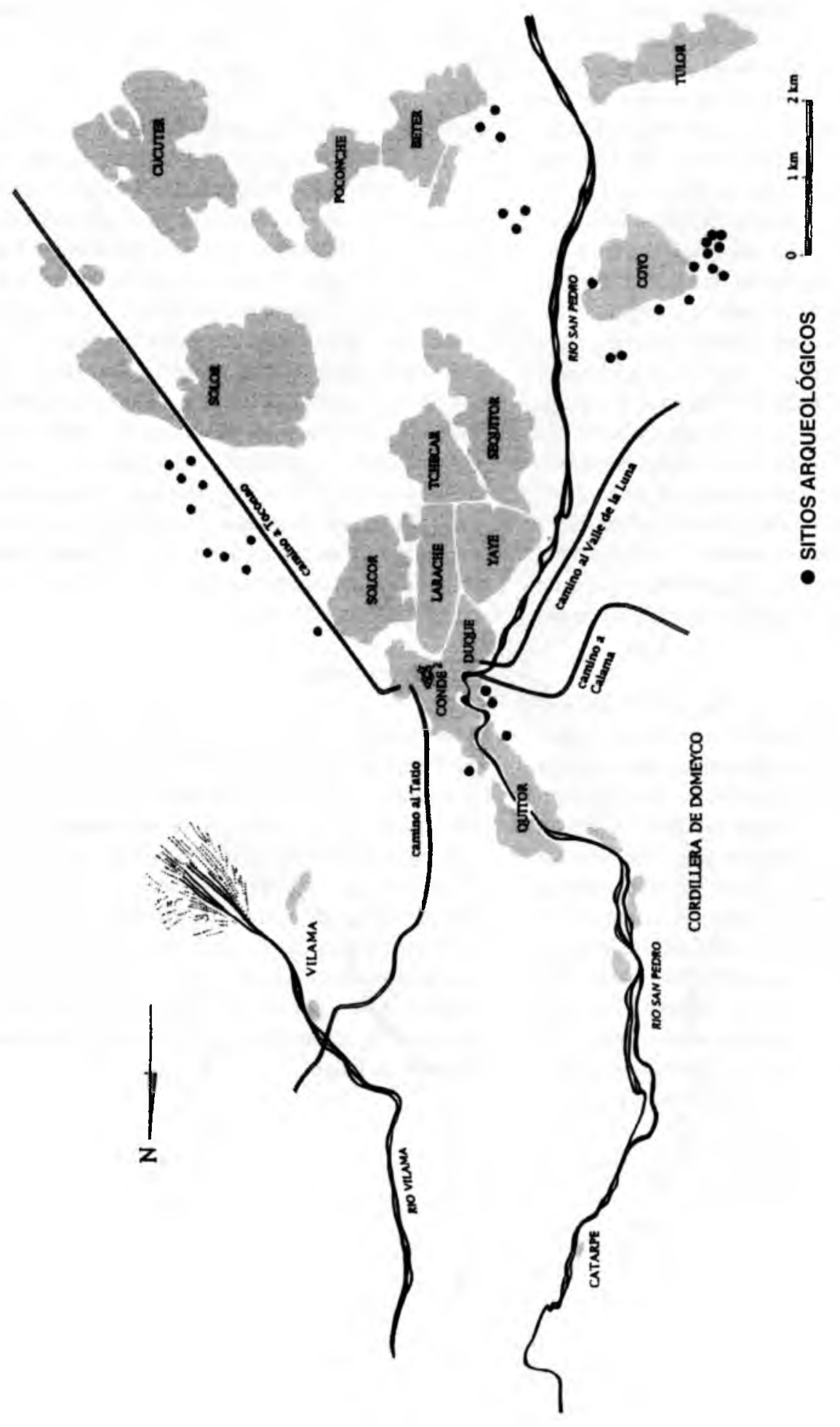

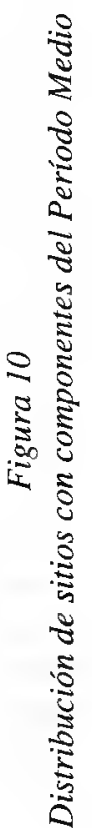


En la Fase Solor (1200 DC - 1470 DC) el patrón de asentamiento nuevamente se expande, después de su reducción en la fase anterior, manifestando presencia ocupacional en los distritos de Beter (un sitio), Coyo (dos sitios en el sector Occidental), Quitor (un sitio), Solcor (un sitio, cfr. Le Paige), Solor (tres sitios) y, por primera vez, aparecen asentamientos en los distritos de Catarpe (dos sitios) y de Vilama (dos sitios) (Fig. 11). La ubicación en que se asientan los sitios fortificados contemporáneos pone de manifiesto una intención estratégica, que tanto pudo estar orientada a la protección de la población y sus recursos, como a algún tipo de control hidráulico de la zona de oasis fluviales, ejercido desde Quitor Pukara en el río San Pedro y desde Vilama 2, en el río Vilama. Ambos sitios ocupan precisamente las gargantas que hacen de puerta de acceso desde las correspondientes quebradas hacia los oasis. Unidades complejas o conjuntos densos fueron construidos en las áreas mencionadas. Todo ésto pone en evidencia que una organización jerárquica de mayor complejidad, empieza a ejercer su hegemonía en el entorno.

En la Fase Catarpe Inka (1470 hasta 1535 DC), el eje sociopolítico se desplaza hacia el sitio Catarpe 11 , con sus instalaciones incaicas ubicadas a la vera del camino inca. El patrón de asentamiento muestra un fortalecimiento de las ocupaciones en la garganta del río San Pedro y del río Vilama, representado por cuatro sitios en Catarpe, además de los dos tambos, y dos sitios en Vilama (Fig. 12). Sin duda, estos lugares siguen siendo los puntos estratégicos para el control político de los oasis de San Pedro de Atacama y Catarpe 11 se configura como el centro administrativo incaico, el que incorpora arquitectónica y jerárquicamente, la residencia del o de los representantes del Inka.

Para la Fase Tardía-Hispánica (posterior a 1535
DC) se conocen dos reducidos establecimientos en Vilama y un gran asentamiento en Beter; a éstos, habría que sumar el ayllu de Conde Duque donde se estableció el centro administrativo hispánico colonial (Fig. 13).

Las determinantes en las modalidades de los patrones de asentamiento durante la época agroalfarera en San Pedro de Atacama estuvieron relacionadas con el manejo del recurso hídrico y con la disponibilidad de espacios colonizables. Las evidencias iniciales de la ocupación humana se manifiestan preferentemente en la esquina suroccidental de la formación de oasis (Tulor); las posteriores ocupaciones van cobrando fuerza en los distritos centrales (Quitor, Solcor, Larache y Séquitor), con una siguiente ocupación de los flancos occidental y oriental (Coyo y Solor), y algo en los distritos centro-meridionales (Tchaputchayna y Beter); en tanto que, la tendencia tardía se extiende a los extremos norte y sur (Catarpe y Beter), a los flancos este y oeste (Solor y Yaye), así como también a Vilama.

\section{Agradecimientos}

Se extiende nuestro reconocimiento a María Elena Noel (1992) por su participación en las prospecciones; a Cecilia Uribe por el análisis de la cerámica, a Varinia Varela por su asesoría en la clasificación cerámica y a Beatríz Cremonte por su colaboración en la preparación de estándares ceramológicos de pastas. Así mismo, se agradece a los Auxiliares del Instituto de Investigaciones Arqueológicas y Museo, muy especialmente a Manuel Abán, por su participación en las prospecciones y reconocimiento de los sitios trabajados por Le Paige. 


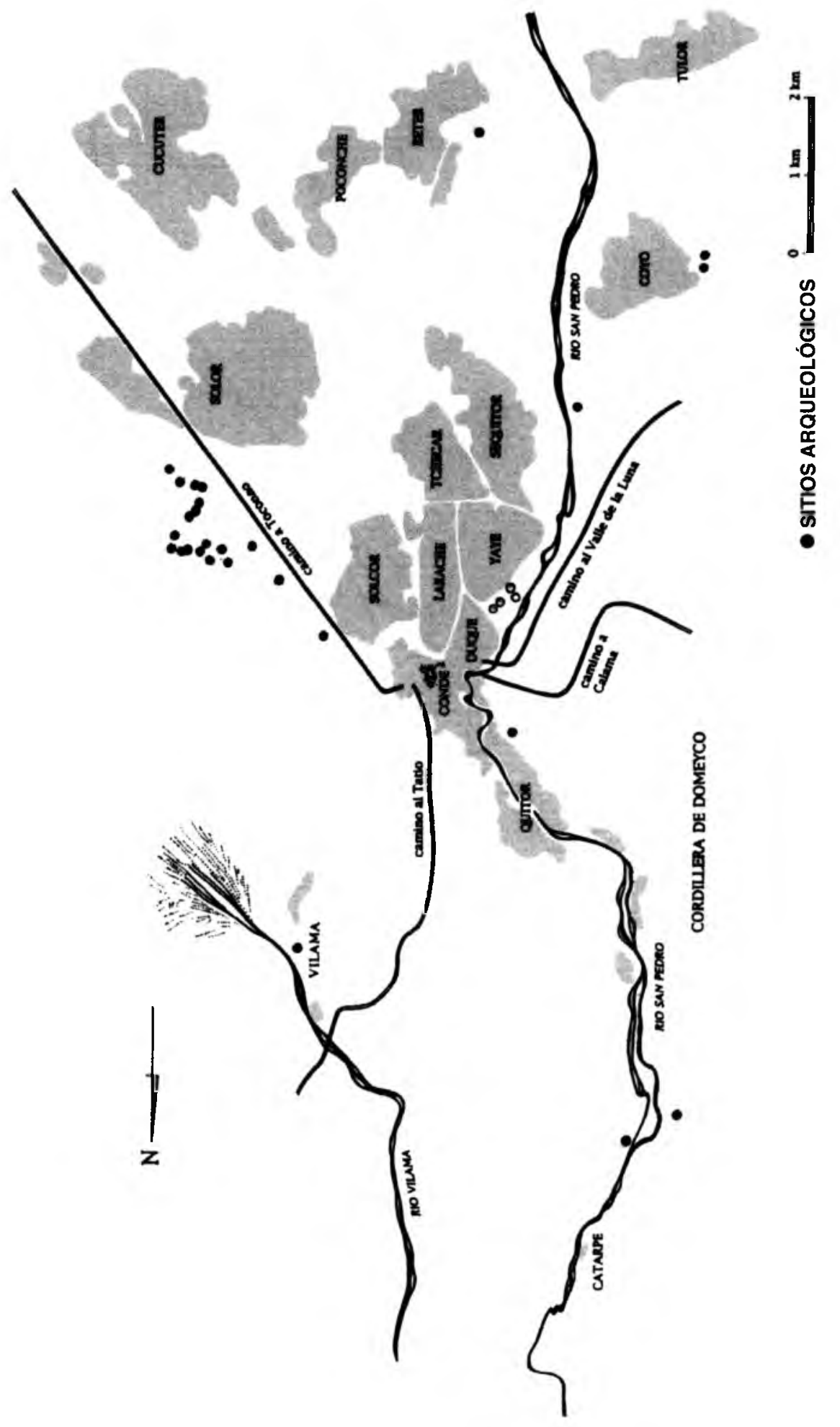

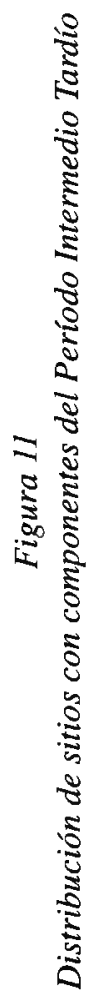




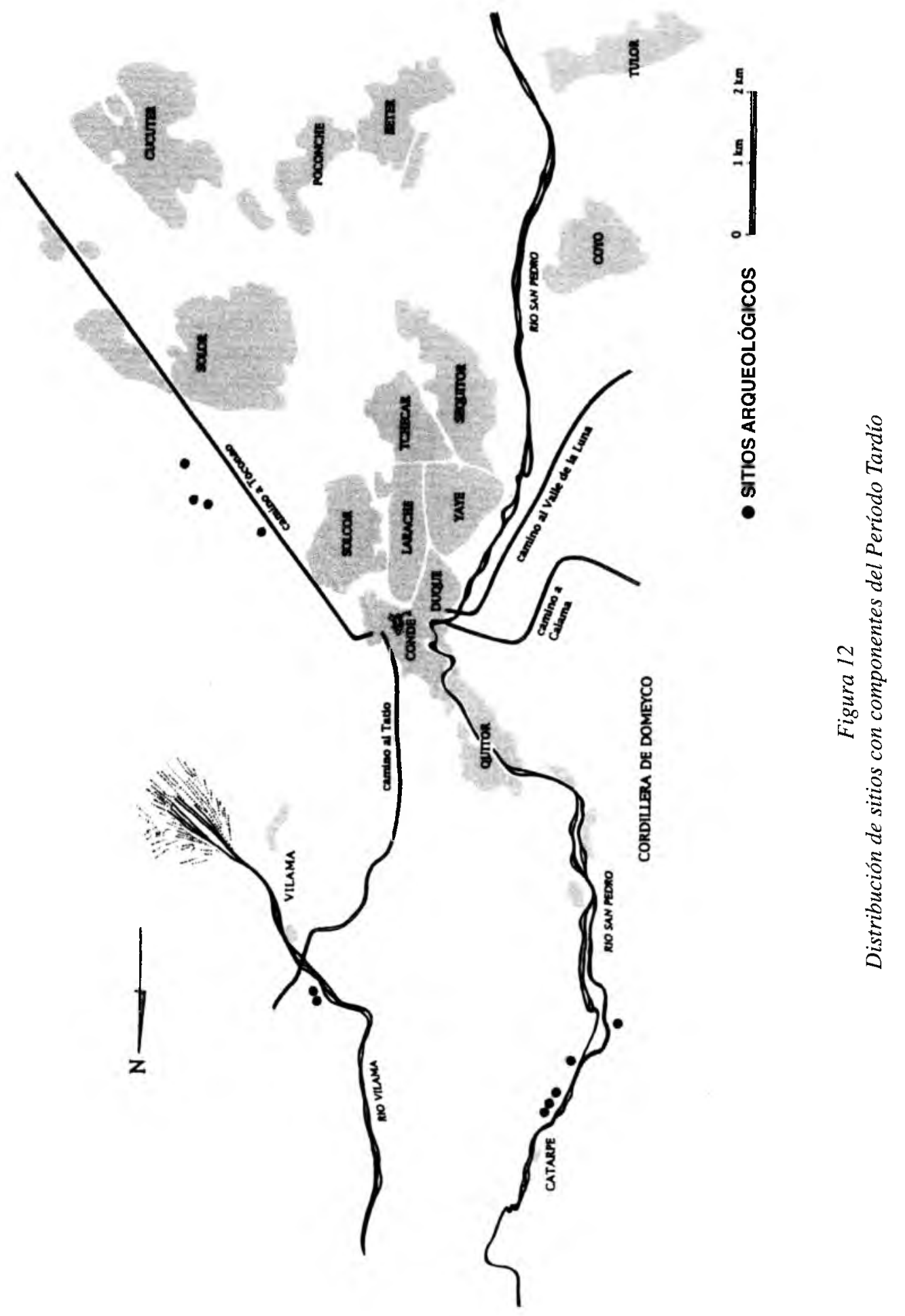




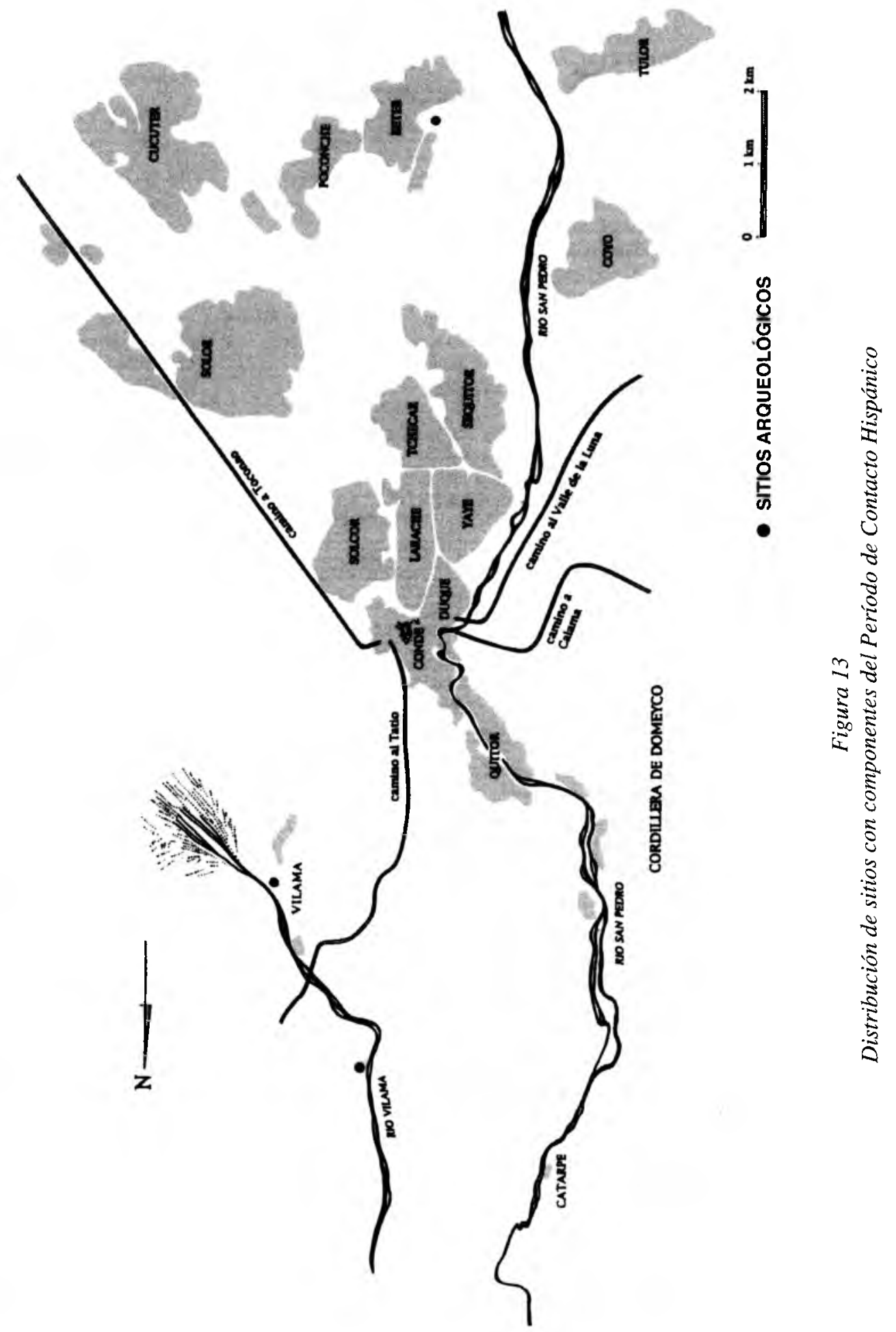




\section{BIBLIOGRAFIA}

\begin{abstract}
ARANDA, $X . \quad$ San Pedro de Atacama: Elementos Diag1961-64 nósticos para un Plan de desarrollo Local. Informaciones Geográficas 11-14 (Número Especial).
\end{abstract}

BERENGUER, J., A. DEZA, A. ROMAN y A. LLAGOSTE1986 RA. La Secuencia de Myriam Tarragó para San Pedro de A tacama: Un Test por Termoluminiscencia. Revista Chilena de Antropología 5: 17-54. Universidad de Chile. Santiago.

BRAVO, L. y A. LLAGOSTERA. Solcor 3: Un Aporte al Co 1986 nocimiento de la Cultura San Pedro. Período 500 al 900 d.C. Chungará $16-$ 17: 323-332.

COSTA, M.A. Reconstitución Física y Cultural de la 1988 Población Tardía del Cementerio de Quitor-6 (San Pedro de Atacama). Estudios Atacameños 9: 99-126.

COSTA, M.A. y A. LlagosteRA. Coyo-3: Momentos Fina1994 les del Período Medio en San Pedro de Atacama. Estudios Atacameños 11: 73107.

LE PAIGE, G. La Antiguedad de una Tumba Compro 1963 bada por Carbono 14 y el Ambiente que lo Rodea. Revista de la Universidad Católica, Año XLVIII, pp.: 167-176. Santiago.

1964 El Precerámico en la Cordillera Atacameña y los Cementerios del Período Agro-alfarero de San Pedro de Atacama. Anales de la Universidad del Norte $\mathrm{N}^{\mathrm{o}}$ 3. Antofagasta.

1965 San Pedro de Atacama y su Zona (14 temas). Anales de la Universidad del Norte $\mathrm{N}^{\mathbf{0}} 4$. Antofagasta.

1974 Informes de Trabajo.Estudios Atacameños 2: 101-104.

1972-73 Tres Cementerios Indígenas en San Pedro de Atacama y Toconao. En Actas del VI Congreso de Arqueología Chilena, Boletín de Prehistoria (Número Especial), pp. 163-187.

LYNCH, T. F. Informes de Trabajo: Tambo Incaico 1977 Catarpe-Este (Informe de Avance). Estudios Atacameños 5: 142-147.
LLAGOSTERA, A., A. M. BARON y L. BRAVO. Investiga 1984 ciones Arqueológicas en Tulor-1. En Primer Simposio de Arqueología Atacameña. Estudios A t a c a m e ñ os 7:133-151.

LLAGOSTERA, A., C.M. TORRES y M.A. COSTA. El Com1988 plejo Psicotrópico en Solcor-3 (San Pedro de Atacama). Estudios Atacameños 9: 61-98.

MOSTNY, G. Ciudades Atacameñas. Boletín del Mu1949 seo Nacional de Historia Natural 24: $125-211$.

MUN̂OZ, E. Restauración del Pukara de Quitor. En 1984 Primer Simposio de Arqueología Atacameña. Estudios Atacameños 7: 253-263.

NOEL, M.E. Prospección de Sitios Arqueológicos 1992 en la Localidad de San Pedro de Atacama. Práctica Profesional. Universidad de Chile, Santiago (MS).

NUÑEZ, L. Registro Regional de Fechas Radiocar1976 bónicas del Norte de Chile. Estudios Atacameños 4: 74-123.

1992 Ocupación arcaica en la Puna de Atacama; Secuencia, movilidad y cambio. Prehistoria Sudamericana. Nuevas Perspectivas. pp 283-308. B. J. Meggers (Ed.) Taraxacum. Washington.

OAKLAND, A. Textiles and Ethnicity: Tiwanaku in San 1992 Pedro de Atacama, North Chile. Latin American Antiquity 3(4): 316-340.

ORELlanA, M. Problemas de la Arqueología de San Pe1963 dro de Atacama y sus Alrededores. En Congreso Internacional de Arqueología de San Pedro de Atacama. Anales de la Universidad del Norte $2: 29-39$.

SERRACINO, G. Tulor-4: 4 Pozos de Sondeo. Estudios 1976 Atacameños 4: 24-31.

SERRACINO, G. y R. STEHBERG. Informes de Trabajo: Pro1973 yecto Guatín. Estudios Atacameños 1: $39-42$.

1974 Investigaciones Arqueológicas en Guatín, San Pedro de Atacama. Estudios Atacameños 2: 7-10. 
TARRAGO, $\mathrm{M}$. 1968
Secuencias Culturales de la Etapa Agroalfarera de San Pedro de Atacama (Chile). En Actas y Memorias del XXXVII Congreso Internacional de Americanistas, Vol. 2, pp.: 119-145. Buenos Aires.
1989

Contribución al Conocimiento Arqueológico de las Poblaciones de los Oasis de San Pedro de Atacama en relación con los otros Pueblos Puneños, en especial, el Sector Septentrional del Valle Calchaquí. Tesis Doctoral. Universidad Nacional de Rosario. Rosario.

\begin{abstract}
ANEXO 1
Los tipos cerámicos numerados del 1 al 14 corresponden a aquellos definidos por el Proyecto El Pukara de Turi: Un testimonio documental de continuidad cultural en la Subárea Circumpuneña (FONDECYT 1022/ 88). Los tipos del 15 al 36 fueron establecidos a través del análisis ceramológico del Proyecto FONDECYT 90/0081.
\end{abstract}

TIPO 1 : Rojo alisado ambas caras.

TIPO 2: Rojo alisado interior/rojo alisado burdo exterior. El término "burdo" define el aspecto rugoso que muestra los vacíos dejados por el arrastre de las inclusiones gruesas sobre la superficie.

TIPO 3 : Variedad Ayquina. Incluye las siguientes combinaciones:

- café-rojizo revestido pulido interior/alisado exterior.

- gris-café revestido pulido interior/alisado exterior.

- café no revestido pulido interior/alisado exterior.

TIPO 4 : Rojo alisado interior/negro alisado exterior.

TIPO 5 : Negro alisado interior/rojo alisado exterior.

TIPO 6 : Negro pulido interior/negro alisado exterior.

TIPO 7 : Gris alisado ambas caras.

TIPO 8 : Negro revestido pulido interior/rojo alisado exterior (variedad Dupont).

TIPO 9 : Rojo revestido pulido ambas caras.

TIPO 10: Rojo revestido pulido interior/café alisado exterior.

TIPO 11: Rojo alisado interior/rojo revestido alisado exterior. Este tipo correspondería al San Pedro Rojo Pintado.

TIPO 12: Rojo revestido alisado interior/rojo alisado exterior.

TIPO 13: Café alisado interior/rojo revestido pulido exterior.

TIPO 14: Negro alisado rasmillado interior/rojo revestido pulido exterior.

TIPO 15: Rojo alisado interior/rojo pulido exterior.

TIPO 16: Decorados.

TIPO 17: Foráneos.

TIPO 18: Rojo alisado ambas caras. (Se diferencia del Tipo 1 por la pasta densa con inclusiones de mica).

TIPO 19: Presenta las mismas características que el anterior, salvo que su tratamiento de superficie es pulido.

TIPO 20: Pasta de aspecto foráneo; sin embargo, las inclusiones son de tipo local.

TIPO 21: Similar al tipo anterior, pero con pasta más fina.

TIPO 22: Vidriados.

TIPO 23: Fragmentos con mucho contenido de mica en su pasta; posiblemente posthispánicos.

TIPO 24: Incisos y/o grabados.

TIPO 25: Esmaltados. 
TIPO 26: Fragmentos cuya pasta es muy densa en inclusiones blancas; el tratamiento de superficie es similar a la del Tipo 1.

TIPO 27: San Pedro Negro Pulido.

TIPO 28: San Pedro Gris Pulido.

TIPO 29: San Pedro Café Pulido.

TIPO 30: Negro Grueso Pulido.

TIPO 31: Gris Grueso Pulido.

TIPO 32: Café Grueso Pulido.

TIPO 33: Variante de los Tipos San Pedro Pulido. El tratamiento de superficie es menos cuidadoso, las paredes son sensiblemente más gruesas y las formas parecen simplificarse (vasijas tronco-cónicas invertidas, cilíndricas y semi-esféricas). La pasta es similar a los San Pedro Pulidos, aunque levemente más gruesa.

TIPO 34 : No clasificados.

TIPO 35 : Cerámica moderna.

TIPO 36 : San Pedro Rojo Pulido.

Tarragó (1989) distingue 30 clases de asociaciones contextuales de las cuales, las 13 primeras y la 26 corresponden a asociaciones entre tipos de alfarería:

Clase 1. Ajuares con cerámica del Tipo Rojo Pulido.

Clase 2. Rojo Pulido y vasijas ordinarias grandes.

Clase 3. Rojo Pulido y Rojo Bruñido.

Clase 4. Rojo Pulido y Negro Pulido.

Clase 5. Negro Pulido temprano, Alisado y Negro Pulido Decorado A.

Clase 6. Negro Pulido clásico, negro Pulido Decorado B.

Clase 7. Negro Pulido y Negro Grabado.

Clase 8. Negro Pulido y Rojo Grabado.

Clase 9. Negro Grabado solo o asociado a Rojo Grabado y Gris Pulido Grueso.

Clase 10. Rojo Grabado solo o asociado a Gris Pulido Grueso.

Clase 11. Gris Pulido Grueso solo o con combinaciones.

Clase 12. Ajuares con ausencia de alfarería o poca frecuencia de tipos alisados.

Clase 13. Roja Violácea sola o con combinaciones.

Clase 26. Urnas Solor. 